\title{
Vanadium (IV and V) Complexes of Reduced Schiff Bases Derived from the Reaction of Aromatic o-Hydroxyaldehydes and Diamines Containing Carboxyl Groups
}

\author{
João Costa Pessoa, ${ }^{*[a]}$ Susana Marcão, ${ }^{\text {[a] }}$ Isabel Correia, ${ }^{\text {[a] }}$ Gisela Gonçalves, ${ }^{\text {[a] }}$ \\ Agnes Dörnyei, ${ }^{[b]}$ Tamás Kiss, ${ }^{*[b]}$ Tamás Jakusch, ${ }^{[b, c]}$ Isabel Tomaz, ${ }^{[a, d]}$ \\ M. Margarida C. A. Castro, ${ }^{[\mathrm{d}]}$ Carlos F. G. C. Geraldes, ${ }^{[\mathrm{d}]}$ and Fernando Avecilla ${ }^{[\mathrm{el}}$
}

Keywords: Salen-like ligands / N,O ligands / Vanadium / Coordination modes / Equilibrium and structural studies

The reduced Schiff bases of salicylaldehyde [and $o$-vanillin (o-van)] with D,L- and L-diaminopropionic acid (DPA), designated by salDPA, and L-2,4-diaminopentanoic acid [ornithine (Orn)], designated by salOrn, as well as the $\mathrm{V}^{\mathrm{IV}} \mathrm{O}^{2+}$ and $\mathrm{V}^{\mathrm{V}} \mathrm{O}_{2}{ }^{+}$complexes of salDPA were prepared. The compounds were characterised in the solid state and in solution. The structure of $\mathrm{H}_{4} \mathrm{SalDPA}^{+} \mathrm{Cl}^{-}$was determined by X-ray diffraction. Complexation of $\mathrm{V}^{\mathrm{IV}} \mathrm{O}^{2+}$ and $\mathrm{V}^{\mathrm{V}} \mathrm{O}_{2}{ }^{+}$with salDPA and salOrn (only the $\mathrm{V}^{\mathrm{IV}} \mathrm{O}$ system) in aqueous solution was studied by potentiometry, UV/Visible spectroscopy and circular dichroism, as well as by EPR spectroscopy for the $\mathrm{V}^{\mathrm{IV}} \mathrm{O}-$
salDPA system and by ${ }^{1} \mathrm{H}$ - and ${ }^{51} \mathrm{~V}$ NMR spectroscopy for the $\mathrm{V}^{\mathrm{V}} \mathrm{O}_{2}$-salDPA system. Stoichiometries and complex formation constants were determined by potentiometry at $25^{\circ} \mathrm{C}$ and $I=0.2 \mathrm{M} \mathrm{KCl}$. Practically only $1: 1$ complexes were formed in both systems with composition (VO) $\mathrm{LH}_{2}$ and (VO)L in the $\mathrm{V}^{\mathrm{IV}} \mathrm{O}-$ salDPA system, and with composition $\left(\mathrm{VO}_{2}\right) \mathrm{LH}$ and $\left(\mathrm{VO}_{2}\right) \mathrm{L}$ in the $\mathrm{V}^{\mathrm{V}} \mathrm{O}_{2}$-salDPA system. Spectroscopic data provided information about the most probable binding modes of each stoichiometry.

( Wiley-VCH Verlag GmbH \& Co. KGaA, 69451 Weinheim, Germany, 2006)

\section{Introduction}

The presence of vanadium in biological systems, its insulin-enhancing action ${ }^{[1-4]}$ and anticancer activity ${ }^{[5-7]}$ has driven a considerable amount of research. Particular interest has been given to the study of the potential benefits of vanadium compounds as oral insulin substitutes for the treatment of diabetes. ${ }^{[8-12]}$ Coordinated ligands should be able to improve the absorption and possibly the transport of vanadium to the cells, reducing the dose necessary for producing an equivalent effect. Several vanadium complexes of the dianionic tetradentate Schiff base salen $\left(N, N^{\prime}\right.$ disalicylideneethylenediamine)-type ligands have been pro

[a] Centro Química Estrutural, Instituto Superior Técnico, Av. Rovisco Pais, 1049-001 Lisboa, Portugal

[b] Department of Inorganic and Analytical Chemistry University of Szeged, PO Box 440, 6701 Szeged, Hungary

[c] Bioinorganic Chemistry Research Group of the Hungarian Academy of Sciences, Department of Inorganic and Analytical Chemistry, University of Szeged, PO Box 440, 6701 Szeged, Hungary

[d] Departamento de Bioquímica, Centro de RMN e Centro de Neurociênciase Biologia Celular, Universidade de Coimbra, 3000 Coimbra, Portugal

[e] Departamento de Química Fundamental, Universidaded de Coruña, Campus de A Zapateira s/n, 15071, A Coruña, Spain

$\square$ Supporting information for this article is available on the WWW under http://www.eurjic.org or from the author. posed for use as insulin-enhancing agents, and for treatment of obesity and hypertension. ${ }^{[13-15]}$ Durai and Saminathan ${ }^{[13]}$ reported the ability of $\mathrm{V}^{\mathrm{IV}} \mathrm{O}($ salen) to reverse the hyperglycemic condition of alloxan-induced diabetic rats to near normal, thereby exerting insulin-like action. However, rats tended to become hypoglycemic, and withdrawal of treatment brought about an immediate return of the hyperglycemia. Oxidovanadium(IV) complexes of hydroxysalen derivatives have also been reported to possess nuclease activity in the presence of an activating agent (mercaptopropionic acid or Oxone). ${ }^{[16]}$

Salen-type ligands present versatile steric, electronic and lipophilic properties. They may be easily prepared by the condensation of two compounds: (i) an aromatic o-hydroxyaldehyde and (ii) a diamine, the hydrophilic-lipophilic balance being easily fine-tuned by choosing the appropriate amine precursors and ring substituents of the aldehyde. However, Schiff base (SB) ligands have the disadvantage that they hydrolyse in solution. This instability can be overcome by the reduction of the SB to give an amine, i.e. ligands often designated as salan compounds. This presents interesting possibilities, as the reduced SB will be more flexible and not restrained to remain planar when coordinated to a metal centre. Moreover, some of the $\mathrm{V}^{\mathrm{IV}} \mathrm{O}^{2+}$ and $\mathrm{V}^{\mathrm{V}} \mathrm{O}_{2}{ }^{+}$ complexes with salan ligands have been shown to be several orders of magnitude more stable than the corresponding salen compounds. ${ }^{[15,17]}$ 
We report the preparation of salan compounds derived from the condensation of salicylaldehyde [in one case also of $o$-vanillin $(o$-van)] with D,L- and L-diaminopropionic acid (DPA), L-2,4-diaminopentanoic acid (L-ornithine) and L2,5-diamino-hexanoic acid (L-lysine), which are designated by salDPA (1), salOrn (2) and salLys (3), respectively, and the preparation of $\mathrm{V}^{\mathrm{IV}} \mathrm{O}$ - and $\mathrm{V}^{\mathrm{V}} \mathrm{O}_{2}$-salDPA complexes. The compounds were characterised in the solid state and in solution. The molecular formulas of two of the salan compounds prepared (salDPA and salOrn) are depicted in Scheme 1.<smiles>O=C(O)C(CCCNCc1ccccc1O)NCc1ccccc1O</smiles>

Scheme 1. Molecular formulae of two of the ligands prepared. Those of salLys (3) and vanDPA (4) are represented in the Supporting Information. The totally protonated compound $\mathbf{1}$ corresponds to $\mathrm{H}_{5} \mathrm{salDPA}^{2+}$. We obtained two different solid compounds: $\mathrm{H}_{3}$ salDPA (1) and $\mathrm{H}_{4}$ salDPA ${ }^{+} \mathrm{Cl}^{-}$(1A). When designating these and the other salan compounds obtained in this work without specific attention to their protonation state, we will omit the protonation state, e.g. we will normally designate $\mathbf{1}$ as salDPA.

Most of the biologically important reactions of vanadium occur in water-based environments such as blood plasma or other biological fluids and intracellular media. Therefore, the knowledge of the distribution and chemical speciation of the vanadium compounds in aqueous solution is of utmost importance. Most of the salen-type ligands and their vanadium complexes prepared so far are not watersoluble. The vanadium compounds prepared using salDPA are moderately soluble in water; therefore, they may be useful for therapeutic use. The salOrn ligand (2) was obtained in a low yield and only a few studies were made using this compound. However, as salLys (3) is not soluble in water or in ethanol/water at least up to $10 \%$ ethanol, this compound was characterised in the solid state but was not further studied.
Studies of moderately water-soluble Schiff bases and their hydrolytically more stable salan derivatives were previously reported, ${ }^{[15,17]}$ namely several $\mathrm{V}^{\mathrm{IV}} \mathrm{O}-$ and $\mathrm{V}^{\mathrm{V}} \mathrm{O}_{2}$-pyran complexes [pyran $=N, N^{\prime}$-ethylenebis(piridoxylaminato)] were prepared and their properties studied. The ligands were found to form basically similar complexes coordinating through the $\mathrm{O}$ and $\mathrm{N}$ atoms $\left(2 \times \mathrm{O}_{\text {phenolate, }} 2 \times\right.$ $\left.\mathrm{N}_{\text {amine/imine }}\right)$. EPR spectroscopic $\left(\mathrm{V}^{\mathrm{IV}} \mathrm{O}-\right.$ pyran system) and ${ }^{1} \mathrm{H}$ - and ${ }^{51} \mathrm{~V}$ NMR spectroscopic $\left(\mathrm{V}^{\mathrm{V}} \mathrm{O}_{2}\right.$-pyran system) studies indicated the presence of various isomeric species in solution. The additional carboxylate group of salDPA may alter the structure and stability of the complexes. In fact salDPA forms very stable complexes with $\mathrm{Cu}^{\mathrm{II}}$ and $\mathrm{Fe}^{\mathrm{III}},{ }^{\mathrm{I}}{ }^{[8]}$ and in this work we also find that it is an effective ligand for $\mathrm{V}^{\mathrm{IV}} \mathrm{O}^{2+}$ and $\mathrm{V}^{\mathrm{V}} \mathrm{O}_{2}{ }^{+}$. Moreover, the pendant carboxylate group may help with the coupling of the salan moiety to other molecules that may target the compound to specific biological sites, thereby anticipating the possibility of minimising its toxicity and increasing its efficacy.

\section{Results and Discussion}

\section{Synthesis and Characterisation}

The reduced SBs 1-2 depicted in Scheme 1 were prepared by the condensation of two equivalents of the appropriate aldehyde derivative with one equivalent of the diamine derivative. Treatment of these condensation products with sodium borohydride resulted in the reduction of the two imine bonds, yielding the reduced SBs (salan compounds) depicted in Scheme 1. The compounds gave good elemental analysis and were characterised by ${ }^{1} \mathrm{H}$ NMR spectroscopy. A reduced SB derived from the reaction of $o$-vanillin and DPA [vanDPA (4)] was also obtained and characterised in the solid state.

Crystals of $\mathrm{H}_{4}$ salDPA $^{+} \mathrm{Cl}^{-}$(1A) suitable for X-ray diffraction studies were obtained and more details are given in the Supporting Information. The amine nitrogen atoms are both protonated and the carboxylate group is not protonated. An ORTEP diagram with the molecular structure is depicted in Figure 1.

The bond lengths found for $\mathbf{1 A}$ are within the expected range, and are similar to those of two related Schiff base compounds, ${ }^{[19]}$ except for the $\mathrm{C}=\mathrm{N}$ distance. In these com-

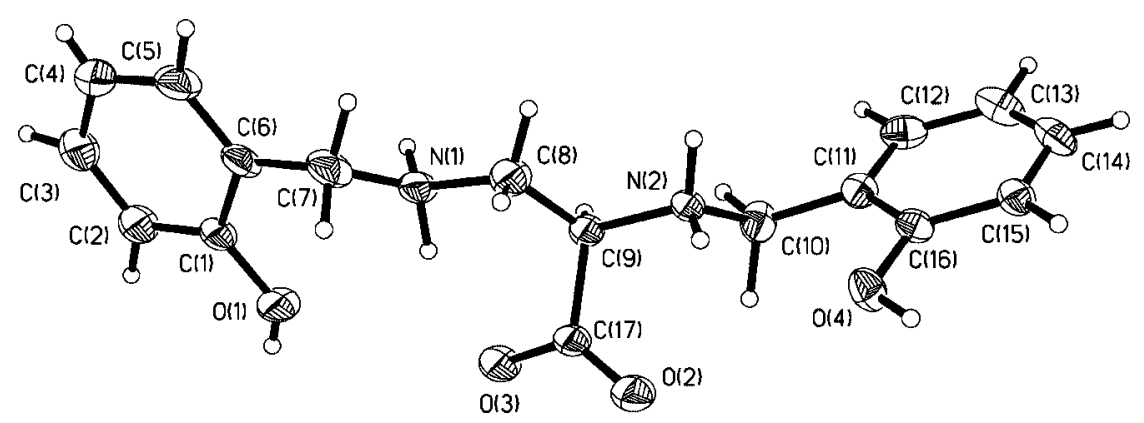

Figure 1. ORTEP diagram of $\mathrm{H}_{4} \mathrm{salDPA}{ }^{+} \cdot \mathrm{Cl}^{-}(\mathbf{1 A})$ with the thermal ellipsoids of the non-hydrogen atoms drawn at the $30 \%$ probability level. 
pounds this distance is 1.248(6) and 1.277(4) $\AA$, and in 1A it corresponds to two single $\mathrm{C}-\mathrm{N}$ bonds [1.491(7) and 1.524(6) $\AA$, for $\mathrm{N}(1)-\mathrm{C}(7)$ and $\mathrm{N}(2)-\mathrm{C}(10)$, respectively].

Some selected IR data for the ligands and vanadium complexes are shown in the Supporting Information (Table $\mathrm{S} 1)^{[20-23]}$. The $v_{\mathrm{as}}(\mathrm{COO})$ bands appear at $1620-1650 \mathrm{~cm}^{-1}$, while the $v_{\mathrm{s}}(\mathrm{COO})$ bands are assigned to the bands observed at $1415-1480 \mathrm{~cm}^{-1}$. The characteristic $v(\mathrm{~V}=\mathrm{O})$ band appears as a strong band at $960 \mathrm{~cm}^{-1}$ in the IR spectrum of $\mathrm{V}^{\mathrm{IV}} \mathrm{O}$ (salDPA). For $\mathrm{Na}\left[\mathrm{V}^{\mathrm{V}} \mathrm{O}_{2}\right.$ (salDPA)] the strong $v(\mathrm{~V}=\mathrm{O})$ bands appear at 880 and $906 \mathrm{~cm}^{-1}$.

\section{Solution Studies}

\section{salDPA and salOrn}

The totally protonated form of compound $\mathbf{1}$ (Scheme 1) corresponds to $\mathrm{H}_{5} \mathrm{salDPA}^{2+}$. The protonation constants and respective $\mathrm{p} K_{\mathrm{a}}$ values derived from the potentiometric titrations are listed in Table 1. These values agree well with those obtained by Jancsó et al., ${ }^{[18]}$ for a different medium. The $\mathrm{p} K_{\mathrm{a}}$ of the carboxyl group is too low to be determined by potentiometric measurements, this is because of the strong electron-withdrawing effect of the neighbouring amino groups and/or H-bond formation involving these groups. In the Supporting Information (Section 2), we include Figure $\mathrm{S} 1$ where the ${ }^{1} \mathrm{H}$ NMR chemical shifts of salDPA are represented as a function of $\mathrm{pD}$. The chemical shift of the proton attached to $\mathrm{C}(9)$ (proton $\mathrm{b}$ ) shows important changes at $\mathrm{pD}<2$, but the protons attached to $\mathrm{C}(8)$ (protons c) also show some much less important changes in this $\mathrm{pH}$ range. The $\mathrm{H}_{4} \mathrm{~L}^{+}$form is dominant in the $\mathrm{pH}$ range $2-5$ and its deprotonation $\left(\mathrm{p} K_{\mathrm{a} 2}=5.91\right)$ is well separated from the following consecutive deprotonation steps. Since practically no change in the UV spectra occurs during this step, this can be assigned to the deprotonation of an amino group. ${ }^{[18]}$ In Figure $\mathrm{S} 1$ it is clear that only the chemical shifts of the protons attached to $\mathrm{C}$ atoms close to the $\mathrm{N}_{\text {amine }}$ atoms show significant changes at $\mathrm{pD} \approx 6$, in particular the proton attached to $\mathrm{C}(9)$ shows important changes. This indicates that $\mathrm{p} K_{\mathrm{a} 2}$ is mainly associated with the deprotonation of atom N(2). Further deprotonation processes are followed by a continuous increase of the absorption bands at 238 and $292 \mathrm{~nm}$, attributed to intramolecular transitions of the phenolate rings. In Figure S1, for $\mathrm{pD}>8$ there is a progressive change in the chemical shifts of all protons (except for proton b) as $\mathrm{pD}$ is increased. Therefore, the three consecutive deprotonations of $\mathrm{H}_{3}$ salDPA involve overlapping deprotonation processes related to the second amino group and the two phenol $\mathrm{OH}$ groups. However, the behaviour of the chemical shifts of the $\mathrm{H}$ atoms of $\mathrm{C}(7)$ (proton $\mathrm{d}$ ) and $\mathrm{C}(8)$ (proton c) suggests that the second $-\mathrm{NH}_{2}{ }^{+}-$group is slightly more acidic than the two phenol protons whose deprotonation occurs at higher $\mathrm{pD}$ values, as shown particularly by the changes in the chemical shifts of the aromatic $\mathrm{H}$ atoms of $C(4)$ and $C(13)$ (protons $f_{1}$ ) and of $C(2)$ and $C(15)$ (protons $\mathrm{f}_{2}$ ) (see Figure $\mathrm{S} 1$ ).

The protonation constants and $\mathrm{p} K_{\mathrm{a}}$ values of salOrn, determined by potentiometry, are also included in Table 2 . The $\mathrm{p} K_{\mathrm{a}}$ values of salOrn (2) are higher than those of salDPA by a factor of $0.3-1.8$ units. Since one of the amino groups is two carbon atoms further from the carboxyl group, when compared with salDPA, the $\mathrm{p} K_{\mathrm{a}}(\mathrm{COOH})$ is higher for salOrn and could be determined by potentiometric measurements. The difference $\mid \mathrm{p} K_{\mathrm{a} 2}{ }^{\text {salOrn }_{-}}$ $\mathrm{p} K_{\mathrm{a} 2}{ }^{\text {salDPA }}$ (equal to 1.8 ) suggests that the $-\mathrm{NH}_{2}{ }^{+}-$group associated with this deprotonation is the one that is closer to the $\mathrm{COO}^{-}$group.

Table 1. Formation constants $\left(\log \beta_{p q r} \text { for species } \mathrm{M}_{p} \mathrm{~L}_{q} \mathrm{H}_{r}\right)^{[\mathrm{a}]}$ for the proton, $\mathrm{V}^{\mathrm{IV}} \mathrm{O}^{2+}$ and $\mathrm{V}^{\mathrm{V}} \mathrm{O}_{2}{ }^{+}$complexes of salDPA and salOrn, ${ }^{[\mathrm{b}]}$ and some derived data $\left(I=0.2 \mathrm{M} \mathrm{KCl}\right.$ and $\left.25^{\circ} \mathrm{C}\right)$.

\begin{tabular}{|c|c|c|c|}
\hline$p q r / \mathrm{H}_{m} \mathrm{~L}^{x} / \mathrm{p} K_{\mathrm{a} n}$ & salDPA & salDPA & salOrn \\
\hline $\begin{array}{l}015 / \mathrm{H}_{5} \mathrm{~L}^{2+} / \mathrm{p} K_{\mathrm{a} 1} \\
014 / \mathrm{H}_{4} \mathrm{~L}^{+} / \mathrm{p} K_{\mathrm{a} 2} \\
013 / \mathrm{H}_{3} \mathrm{~L} / \mathrm{p} K_{\mathrm{a} 3} \\
012 / \mathrm{H}_{2} \mathrm{~L}-/ \mathrm{p} K_{\mathrm{a} 4} \\
011 / \mathrm{HL}^{2-} / \mathrm{p} K_{\mathrm{a} 5} \\
010 / \mathrm{L}^{3-} /-\end{array}$ & $\begin{array}{l}-K<1.6 \\
35.54(6) / 5.91 \\
29.60(6) / 8.45 \\
21.15(6) / 10.07 \\
11.09(9) / 11.09\end{array}$ & & $\begin{array}{l}40.31(9) / 1.70 \\
38.61(8) / 7.71 \\
30.90(6) / 8.84 \\
22.06(6) / 10.45 \\
11.61(9) / 11.61\end{array}$ \\
\hline$p q r / \mathrm{M}_{p} \mathrm{~L}_{q} \mathrm{H}_{r}^{x[\mathrm{c}]}$ & $\log \beta\left(\mathrm{V}^{\mathrm{IV}} \mathrm{O}^{2+}\right)^{[\mathrm{d}]}$ & $\log \beta\left(\mathrm{V}^{\mathrm{V}} \mathrm{O}_{2}^{+}\right) / \mathrm{p} K_{\mathrm{a}}$ & $\log \beta\left(\mathrm{V}^{\mathrm{IV}} \mathrm{O}^{2+}\right) / \mathrm{p} K_{\mathrm{a}}$ \\
\hline $\begin{array}{l}112 /(\mathrm{VO}) \mathrm{LH}_{2} \\
111 /(\mathrm{VO}) \mathrm{LH}^{-} \\
110 /(\mathrm{VO}) \mathrm{L}^{2-} \\
210 /(\mathrm{VO})_{2} \mathrm{~L} \\
112 /\left\{\left(\mathrm{VO}_{2}\right) \mathrm{LH}_{2}\right\}^{[\mathrm{d}]} \\
111 /\left(\mathrm{VO}_{2}\right) \mathrm{LH}^{-} \\
110 /\left(\mathrm{VO}_{2}\right) \mathrm{L}^{2-}\end{array}$ & $\begin{array}{l}31.28(3) \\
- \\
23.39(3) \\
25.7(3)\end{array}$ & $\begin{array}{l}\{48.1(2)\}^{[\mathrm{e}]} / 5.08 \\
43.02(9) / 8.62 \\
34.40(9)\end{array}$ & $\begin{array}{l}33.23(3) / 6.33 \\
26.9(1) / 5.9 \\
20.99(6) \\
-\end{array}$ \\
\hline
\end{tabular}

[a] Three times the standard deviation is reported in parentheses. [b] A figure with a species distribution diagram for the complexes formed in the $\mathrm{V}^{\mathrm{IV}} \mathrm{O}-$-salOrn system is included in Section 4 of the Supporting Information. [c] $\mathrm{M}=(\mathrm{VO})$ for $\mathrm{V}^{\mathrm{IV}} \mathrm{O}$ complexes and $\mathrm{M}=$ $\left(\mathrm{VO}_{2}\right)$ for $\mathrm{V}^{\mathrm{V}} \mathrm{O}_{2}$ complexes. [d] One of the "good" equilibrium models obtained with PSEQUAD from the potentiometric data included stoichiometry (VO) $\mathrm{LH}_{-1}$ with $\log \beta=12.92$ (other constants have similar $\log \beta$ values). However, for this different model, (VO) $\mathrm{LH}_{-1}$ starts forming at $\mathrm{pH}=9$ and this is not compatible with the Vis spectroscopy and $\mathrm{CD}$ results. $[\mathrm{e}] \mathrm{A} \mathrm{V}^{\mathrm{V}}-\mathrm{salDPA}$ complex forms at $\mathrm{pH}<\mathrm{ca}$. 5.5 , but precipitation of a grey solid and the possible occurrence of redox reactions precluded the reliable determination of its stoichiometry and $\log \beta$. 
Table 2. Spin Hamiltonian parameters for the $\mathrm{V}^{\mathrm{IV}} \mathrm{O}$-salDPA complexes, obtained by computer simulation of the experimental spectra, and $A_{z}$ est values estimated for particular binding modes.

\begin{tabular}{|c|c|c|c|c|}
\hline & $\begin{array}{l}g_{z}^{[\mathrm{a}]} \\
g_{x, y}^{[\mathrm{a}]}\end{array}$ & $\begin{array}{l}A_{z}\left(\times 10^{4} \mathrm{~cm}^{-1}\right)^{[\mathrm{a}]} \\
A_{x, y}\left(\times 10^{4} \mathrm{~cm}^{-1}\right)^{[\mathrm{a}]}\end{array}$ & Possible binding modes & $\begin{array}{l}A_{z}^{\text {est }} \\
\left(\times 10^{4} \mathrm{~cm}^{-1}\right)\end{array}$ \\
\hline \multirow[t]{2}{*}{$\mathrm{VOLH}_{2}$ (II) } & 1.948 & 171.1 & $\left(\mathrm{COO}^{-}, \mathrm{N}_{\text {amine }}, 2 \times \mathrm{H}_{2} \mathrm{O}\right)_{\mathrm{eq}}$ & 173.3 \\
\hline & 1.963 & 50.9 & $\left(\mathrm{O}_{\text {Phen }}^{-}, \mathrm{N}_{\text {amine }}, 2 \times \mathrm{H}_{2} \mathrm{O}\right)_{\mathrm{eq}}\left(\mathrm{COO}^{-}\right)_{\mathrm{ax}}$ & 170.2 \\
\hline \multirow[t]{2}{*}{ VOL (IIIA) } & 1.944 & 167.9 & $\left(\mathrm{COO}^{-}, 2 \times \mathrm{O}_{\text {Phen }}^{-}, \mathrm{H}_{2} \mathrm{O}\right)_{\mathrm{eq}}\left(\mathrm{N}_{\text {amine }}\right)_{\mathrm{ax}}$ & 165.5 \\
\hline & 1.978 & 58.0 & & \\
\hline \multirow[t]{2}{*}{ VOL (IIIB) } & 1.954 & 161.4 & $\left(2 \times \mathrm{O}_{\text {Phen }}^{-}, \mathrm{COO}^{-}, \mathrm{N}_{\text {amine }}\right)_{\mathrm{eq}}\left(\mathrm{N}_{\text {amine }}\right)_{\mathrm{ax}}$ & 160.0 \\
\hline & 1.978 & 57.2 & $\left(2 \times \mathrm{N}_{\text {amine }}, \mathrm{COO}^{-}, \mathrm{O}_{\text {Phen }}^{-}\right)_{\mathrm{eq}}\left(\mathrm{O}_{\text {Phen }}^{-}\right)_{\mathrm{ax}}$ & 161.2 \\
\hline
\end{tabular}

[a] Spin Hamiltonian parameters obtained by the simulation of the experimental spectra by using the computer programme of Rockenbauer and Korecz. ${ }^{[30]}$

\section{$V^{\text {IVO Complexes }}$}

The complex formation constants calculated from the potentiometric titrations carried out at different vanadium/ salDPA ratios are also included in Table $1 .{ }^{[24]}$ Slow equilibration of the solutions only occurred at $\mathrm{pH}>10.5$ (some potentiometric measurements) or at $\mathrm{pH}>11$ (some spectroscopic measurements). With $\mathrm{V}^{\mathrm{IV}} \mathrm{O}^{2+}$ the concentration distribution diagram (Figure 2) includes the stoichiometries (oxidation state and charges omitted): $\mathrm{VO},(\mathrm{VO}) \mathrm{LH}_{2}$, $(\mathrm{VO})_{2} \mathrm{~L}$ (minor species) and (VO)L. For $\mathrm{pH}>$ ca. 12 the $\mathrm{CD}$ spectra recorded indicate the formation of a distinct $\mathrm{V}^{\mathrm{IV}} \mathrm{O}$-salDPA complex [stoichiometry probably $(\mathrm{VO}) \mathrm{LH}_{-1}$ ]; however, a reliable $\log \beta$ for this species could not be obtained (see below).

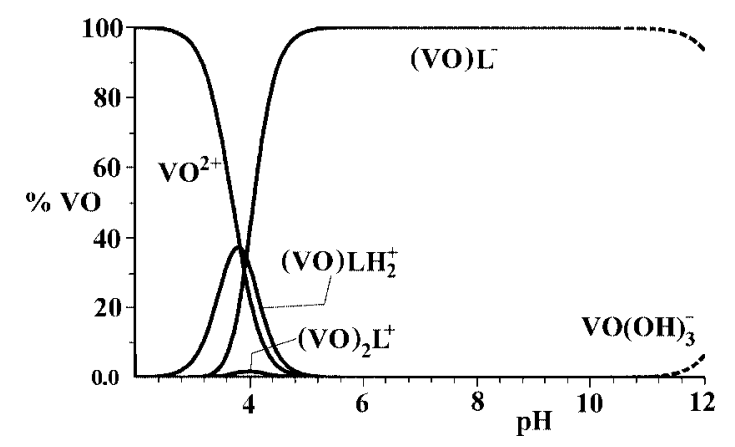

Figure 2. Species distribution diagram for the complexes formed in the $\mathrm{V}^{\mathrm{IV}} \mathrm{O}-$ salDPA system for solutions for which $C_{\mathrm{VO}}=1.0 \mathrm{mM}$ and $\mathrm{L} / \mathrm{M}=1\left(25^{\circ} \mathrm{C}\right.$ and $\left.I=0.2 \mathrm{M} \mathrm{KCl}\right)$.

It is clear from the speciation diagram that the salDPA ligand forms very stable complexes with $\mathrm{V}^{\mathrm{IV}} \mathrm{O}^{2+}$, its hydrolysis products are not formed in measurable concentration at least in the $\mathrm{pH}$ range $2-11$ and $(\mathrm{VO}) \mathrm{L}^{-}$corresponds to ca. $100 \%$ of total $\mathrm{V}$ in the $\mathrm{pH}$ range $5-11$ (at the experimental conditions specified). In (VO) $\mathrm{LH}_{2}{ }^{+}$the tridentate coordination of the ligand seems to be the most probable, then by the cooperative deprotonation of the other half of the molecule a significant rearrangement of the coordinating donors occurs, which results in the formation of a joint chelate-ring system (for the possible binding modes see later).

Potentiometric $\mathrm{pH}$ measurements were also carried out to determine the equilibrium model and formation constants for the $\mathrm{V}^{\mathrm{IV}} \mathrm{O}-$ salOrn system. The best model includes the stoichiometries $(\mathrm{VO}) \mathrm{LH}_{2},(\mathrm{VO}) \mathrm{LH}$ and $(\mathrm{VO}) \mathrm{L}$; the cor- responding $\log \beta$ values are included in Table 2 , and a calculated species distribution diagram is shown in the Supporting Information (Section 3, Figure S2). Compound salOrn also forms stable complexes with $\mathrm{V}^{\mathrm{IV}} \mathrm{O}^{2+}$, but the hydrolysis products of oxidovanadium(IV), namely $\left[(\mathrm{VO})_{2}(\mathrm{OH})_{5}^{-}\right]_{n}$ and $\mathrm{VO}(\mathrm{OH})_{3}{ }^{-}{ }^{[25]}$ have a much higher relative importance in the $\mathrm{pH}$ range for the formation of species VOL in the $\mathrm{V}^{\mathrm{IV}} \mathrm{O}-$ salOrn system than for the $\mathrm{V}^{\mathrm{IV}} \mathrm{O}-$ salDPA system. This results from the lower stability of this VOL species, as one ring of the joint chelate system formed with salOrn is larger than that formed with salDPA (the carbon chain between the two NH groups is two carbon atoms longer in Orn than in DPA).

Figure 3 includes some of the $\mathrm{CD}$ spectra recorded in solutions containing $\mathrm{V}^{\mathrm{IV}} \mathrm{O}^{2+}$ and sal-L-DPA. Globally the $\mathrm{CD}$ spectra agree well with the speciation diagram included in Figure 2. Up to $\mathrm{pH}$ 2.60, as the only V-containing species present in solution is $\mathrm{VO}\left(\mathrm{H}_{2} \mathrm{O}\right)_{5}{ }^{2+}$, the $\mathrm{CD}$ signal in the wavelength range 400-1000 $\mathrm{nm}$ (where vanadium-related bands are expected to show up) is almost zero. As (VO)$\mathrm{LH}_{2}{ }^{+}$forms, spectra with the band pattern $(-,+,-)$are recorded up to $\mathrm{pH}$ ca. 3.4 with $\lambda_{\max }<400 \mathrm{~nm}\left(\Delta \varepsilon_{\mathrm{m}}<0\right)$, ca. $565 \mathrm{~nm}\left(\Delta \varepsilon_{\mathrm{m}}>0\right)$ and ca. $790 \mathrm{~nm}\left(\Delta \varepsilon_{\mathrm{m}}<0\right)$. For $\mathrm{pH}>$ 3.5 and up to 5.0 , the band pattern gradually changes (see Figure 3), but in the $\mathrm{pH}$ range $5-10.5$ the $\mathrm{CD}$ spectra remain the same, with two main bands at $585 \mathrm{~nm}\left(\Delta \varepsilon_{\mathrm{m}}=\right.$ $\left.-0.23 \mathrm{~mol}^{-1} \mathrm{dm}^{-3} \mathrm{~cm}^{-1}\right)$ and $945 \mathrm{~nm} \quad\left(\Delta \varepsilon_{\mathrm{m}}=\right.$ $+1.46 \mathrm{~mol}^{-1} \mathrm{dm}^{-3} \mathrm{~cm}^{-1}$ ), and only show small changes in the pH range 10.5-11.5.

The PSEQUAD computer programme ${ }^{[24]}$ and the CD spectra obtained at different $\mathrm{pH}$ values were used to calculate the $\log \beta$ and/or the spectrum of each individual species formed in the $\mathrm{V}^{\mathrm{IV}} \mathrm{O}-$ salDPA system. The calculated $\log \beta$ values agree reasonably well with those obtained from the potentiometry (within $\pm 0.1 \log$ unit), and reasonable CD spectra could be calculated for $\mathrm{VOLH}_{2}$ and VOL (see Figure $3 \mathrm{~d}$ ). This confirms that the speciation model proposed and the stability constants calculated from the potentiometric measurements are correct and reliable.

Figure 4 includes some of the visible absorption (Vis) spectra recorded with solutions containing $\mathrm{V}^{\mathrm{IV}} \mathrm{O}^{2+}$ and salDPA. Globally the Vis spectra also agree well with the speciation diagram included in Figure 2. At $\mathrm{pH}<2.60$ the Vis spectra are quite similar to the spectrum of VO$\left(\mathrm{H}_{2} \mathrm{O}\right)_{5}{ }^{2+}$ (see Figure 4a). For $\mathrm{pH}>2.6$ bands II $\left(\mathrm{d}_{x y} \rightarrow\right.$ 

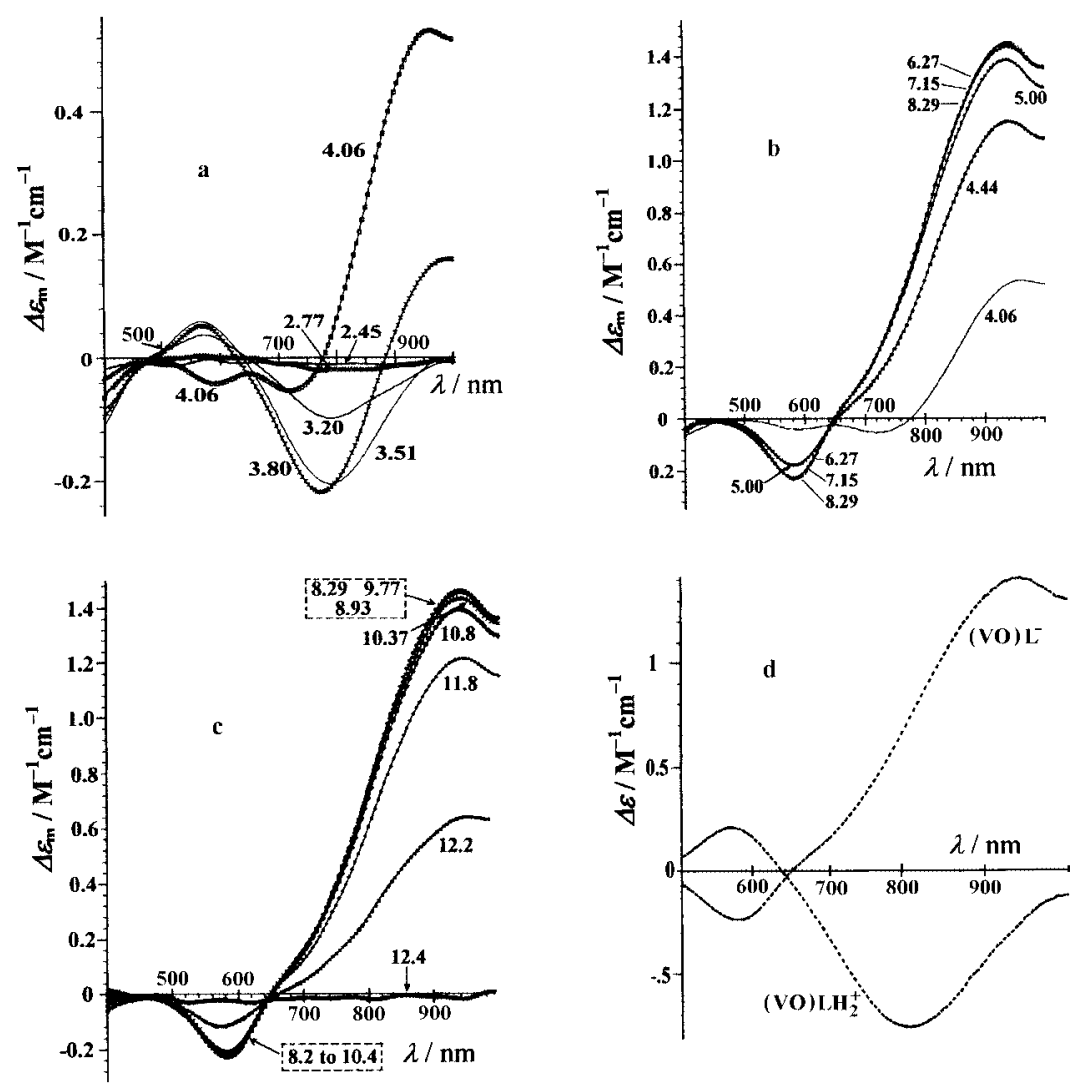

Figure 3. In a, b and c some $\mathrm{CD}$ spectra recorded for the $\mathrm{V}^{\mathrm{IV}} \mathrm{O}-$ salDPA system at a 1:1 metal ion/ligand ratio at several $\mathrm{pH}$ values (indicated) and $C_{\mathrm{VO}}=1 \mathrm{~mm}$ are represented. The $\Delta \varepsilon_{\mathrm{m}}$ values recorded at $\mathrm{pH}=1.96,2.18,2.45,12.4$ are close to zero. Spectra in $\mathrm{d}$ are the individual $\mathrm{CD}$ spectra calculated for stoichiometries (VO) $\mathrm{LH}_{2}$ and $(\mathrm{VO}) \mathrm{L}$ by the PSEQUAD programme ${ }^{[24]}$ from the experimental CD spectra and the equilibrium constants included in Table 2.

$\left.\mathrm{d}_{x^{2}-y^{2}}\right)$ and I $\left(\mathrm{d}_{x y} \rightarrow \mathrm{d}_{x z}, \mathrm{~d}_{y z}\right)$ separate gradually, indicating an increase in the field strength. In the $\mathrm{pH}$ range 5.5-11.0 the Vis spectra do not change much (Figure $4 \mathrm{~b})$ showing two bands at ca. $575 \mathrm{~nm}\left(\varepsilon_{\mathrm{m}} \approx 65 \mathrm{~mol}^{-1} \mathrm{dm}^{-3} \mathrm{~cm}^{-1}\right)$ and ca. $910 \mathrm{~nm}\left(\varepsilon_{\mathrm{m}} \approx 43 \mathrm{~mol}^{-1} \mathrm{dm}^{-3} \mathrm{~cm}^{-1}\right)$, which indicate the presence of a single predominating species, VOL.

There is an important increase in the absorbance at ca. $400 \mathrm{~nm}$ between $\mathrm{pH}$ ca. 2.6 and 3.0, a less important one between 3.0 and 4.0, and then not much change up to $\mathrm{pH}$ 12 (Supporting Information, Section 5, Figure S3). This means that the equatorial coordination of the $\mathrm{O}^{-}$Phen donors is already important at relatively low $\mathrm{pH}$, and its contribution to the $\varepsilon_{\mathrm{m}}$ values at $380-400 \mathrm{~nm}$ does not increase at $\mathrm{pH}>4.0$. At $\mathrm{pH}>5$ the absorbance at ca. $400 \mathrm{~nm}$ is sensitive to small percentages of hydrolysis or oxidation of the metal ion, but for this system the $\varepsilon_{\mathrm{m}}$ values do not change much in this $\mathrm{pH}$ range.

EPR spectra were measured in "frozen" solutions $(77 \mathrm{~K})$ to check the speciation model and to elucidate the binding modes of the species. Some of the EPR spectra obtained for the $\mathrm{V}^{\mathrm{IV}} \mathrm{O}$-salDPA system, in the region corresponding to $M_{\mathrm{I}}=5 / 2$ and $7 / 2$, are depicted in Figure 5. Table 2 shows the spin Hamiltonian parameters obtained by simulation of the experimental spectra. For the $\mathrm{V}^{\mathrm{IV}} \mathrm{O}-$-systems Chasteen ${ }^{[26]}$ developed an additivity rule to estimate the hyperfine coupling constant $A_{z}^{\text {est }}$ [Equation (1)], on the basis of the contributions $A_{z, i}$ of each of the four equatorial donor groups. The estimated accuracy of $A_{z}^{\text {est }}$ is $\pm 3 \times 10^{-4} \mathrm{~cm}^{-1}$.

$$
A_{z}^{\text {cst }}=\sum_{i=1}^{4} A_{2, i}
$$

Most of the $A_{z, i}$ relevant for this work were presented by Chasteen. ${ }^{[26]}$ The contribution of the carboxylate $\left(\mathrm{COO}^{-}\right)$ donor in Equation (1) was estimated by Chasteen as $42.7 \times 10^{-4} \mathrm{~cm}^{-1}$, on the basis of the $A_{z}$ of the VO(oxalato) $2_{2-}^{2-}$ complex, assuming that the four $\mathrm{COO}^{-}$groups coordinate equatorially. However, the solution structure presumably involves the set $\left(3 \times \mathrm{COO}^{-}, \mathrm{H}_{2} \mathrm{O}\right)_{\mathrm{eq}}{ }^{[27]}$ so this contribution should be $42.1 \times 10^{-4} \mathrm{~cm}^{-1}$, the value used in the present work. This data can be used to establish the most probable binding mode of the complexes formed, but care must be taken as the contributions of the donor groups to the hyperfine coupling may depend e.g. on their orientation, ${ }^{[28]}$ or the charge of the ligand. ${ }^{[29]}$ The influence of the axial donor groups (if any) is not taken into account.

Table $2^{[30]}$ summarises the EPR parameters obtained, mostly from the simulation of the spectra by using the computer programme of Rockenbauer and Korecz. ${ }^{[30]}$ Globally the EPR spectra (Figure 5) agree well with the speciation diagram depicted in Figure 2. Namely, for $\mathrm{pH}<3$ the only species detected is the aqua complex $\left[\mathrm{VO}\left(\mathrm{H}_{2} \mathrm{O}\right)_{5}{ }^{2+} \equiv \mathrm{VO} \equiv\right.$ 

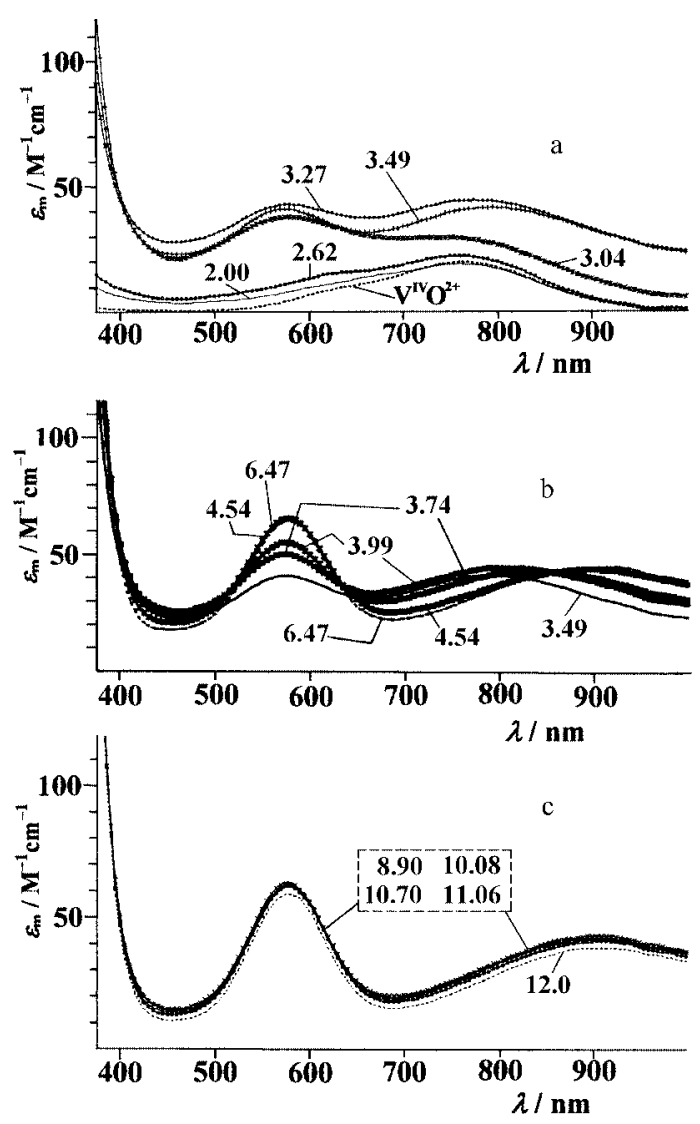

Figure 4. Some of the Vis absorption spectra recorded with aqueous solutions containing $\mathrm{V}^{\mathrm{IV}} \mathrm{O}^{2+}$ and salDPA at a $1: 1$ metal ion/ ligand ratio at several $\mathrm{pH}$ values (indicated) and $C_{\mathrm{VO}}$ ca. $3 \mathrm{~mm}$.

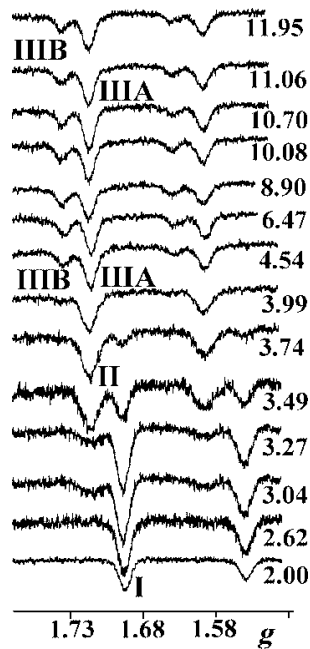

Figure 5. High field region of the EPR spectra $(77 \mathrm{~K})$ of frozen solutions containing $\mathrm{V}^{\mathrm{IV}} \mathrm{O}^{2+}$ and salDPA at several $\mathrm{pH}$ values, with $\mathrm{L} / \mathrm{M}=1$ and $C_{\mathrm{VO}}$ ca. $3 \mathrm{~mm}$. Four main components are detected: I- $\left[\mathrm{VO}\left(\mathrm{H}_{2} \mathrm{O}\right)_{5}\right]^{2+}$, II-(VO) $\mathrm{LH}_{2}{ }^{+}$, IIIA-(VO)L $\mathrm{L}^{-}$and IIIB-(VO)L $\mathrm{L}^{-}$.

I]. At $\mathrm{pH}=3.04$, besides a signal for $\mathrm{VO}$, a signal corresponding to (VO) $\mathrm{LH}_{2}{ }^{+}$(II) can already be detected. At $\mathrm{pH}$ 3.49 the signals corresponding to $\mathrm{VO}$ and $(\mathrm{VO}) \mathrm{LH}_{2}{ }^{+}$show similar intensities, but it should be noted that one of the signals corresponding to (VO) $\mathrm{L}^{-}$(IIIA) also starts appear- ing in this field range. In the pH range ca. 4.5-12 only two EPR components, designated by IIIA and IIIB and corresponding to $A_{z}$ values of 167.9 and $161.4 \times 10^{-4} \mathrm{~cm}^{-1}$, respectively, are detected. Their relative intensity is always the same so they must correspond to isomeric structures of the same stoichiometry, (VO) $\mathrm{L}^{-}$. Up to $\mathrm{pH} 12$ apparently no other species forms, and this is consistent with the Vis and $\mathrm{CD}$ spectra obtained. If any small amount of VO$(\mathrm{OH})_{3}{ }^{-}$is present at high $\mathrm{pH}$, as its $A_{z}$ is ca. $162 \times 10^{-4} \mathrm{~cm}^{-1}$, it would not be distinguished from the lines of $(\mathrm{VO}) \mathrm{L}^{-}$ (IIIB).

It has been previously emphasised ${ }^{[25]}$ that, as the $\mathrm{V}$ atom in most oxidovanadium(IV) complexes is a stereogenic centre, most complexes in solution correspond to two enantiomers. If the ligand contains stereogenic centres and/or if one of the coordinating atoms becomes a stereogenic centre, several isomers corresponding to the same binding mode necessarily form. This is the case of the $\mathrm{V}^{\mathrm{IV}} \mathrm{O}$-salDPA system where $C(9)$ is a stereogenic centre. Moreover, for the same stoichiometry more than one type of binding mode may form. Some may yield distinct EPR signals, others not.

Species (VO) $\mathrm{LH}_{2}{ }^{+}$may correspond to binding modes [( $\left.\left.\mathrm{COO}^{-}, \mathrm{N}_{\text {amine, }}, 2 \times \mathrm{H}_{2} \mathrm{O}\right)_{\text {eq }}\left(\mathrm{N}_{\text {amine }} \text { or } \mathrm{O}_{\text {Phen }}\right)_{\mathrm{ax}}\right]$ BMa, $\left[\left(\mathrm{O}_{\text {Phen }}, \mathrm{N}_{\text {amine, }}, 2 \times \mathrm{H}_{2} \mathrm{O}\right)_{\mathrm{eq}}\left(\mathrm{H}_{2} \mathrm{O} \text { or } \mathrm{COO}^{-}\right)_{\mathrm{ax}}\right] \mathbf{B M b}$, or $\left[\left(\mathrm{O}_{\text {Phen }}, \mathrm{COO}^{-}, 2 \times \mathrm{H}_{2} \mathrm{O}\right)_{\text {eq }}\left(\mathrm{N}_{\text {amine }}\right)_{\text {ax }}\right]$ BMc (see Scheme 2$)$. These binding modes correspond to $A_{z}{ }^{\text {est }}$ values of 173.5 , 170.2 or $172.3 \times 10^{-4} \mathrm{~cm}^{-1}$, respectively. The Vis spectra (Figure 4) indicate a significant equatorial coordination of $\mathrm{O}_{\text {Phen }}$ starting at $\mathrm{pH}<3$; this rules out BMa1 and BMa2. As the calculated $\mathrm{CD}$ spectrum for $\mathrm{VOLH}_{2}$ is quite strong (Figure 3d), this suggests that the $\mathrm{COO}^{-}$group is coordinated equatorially, since this group should induce a strong $\mathrm{CD}$ effect and is near the stereogenic centre. Therefore, the predominant binding mode is probably $\mathbf{B M c}$, where a set of (5+6)-membered chelate rings forms, the part of the salDPA molecule involved in the coordination being the one closer to the stereogenic centre.

Species (VO) $\mathrm{L}^{-}$involves at least two types of isomers, corresponding to species IIIA $\left(A_{z}=167.9 \times 10^{-4} \mathrm{~cm}^{-1}\right)$ and IIIB $\left(A_{z}=161.4 \times 10^{-4} \mathrm{~cm}^{-1}\right)$ detected in the EPR spectra (e.g. Figure 5). Species with binding mode $\left[\left(2 \times \mathrm{O}_{\mathrm{Phen}}\right.\right.$, $\left.\left.2 \times \mathrm{N}_{\text {amine }}\right)_{\mathrm{eq}}\left(\mathrm{H}_{2} \mathrm{O} \text { or } \mathrm{COO}^{-}\right)_{\mathrm{ax}}\right]$ correspond to $A_{z}^{\text {est }}=$ $157.9 \times 10^{-4} \mathrm{~cm}^{-1}$, quite different from the experimental $A_{z}$; therefore, this binding mode does not form significantly. Species IIIB may correspond to binding modes such as $\left[\left(\mathrm{O}_{\text {Phen }}, \mathrm{COO}^{-}, 2 \times \mathrm{N}_{\text {amine }}\right)_{\mathrm{eq}}\left(\mathrm{O}_{\text {Phen }}\right)_{\mathrm{ax}}\right](\mathbf{B M e})$ corresponding to $A_{z}^{\text {est }}=161.2 \times 10^{-4} \mathrm{~cm}^{-1}$, or $\left[\left(2 \times \mathrm{O}_{\text {Phen }}, \mathrm{COO}^{-}\right.\right.$, $\left.\left.\mathrm{N}_{\text {amine }}\right)_{\mathrm{eq}}\left(\mathrm{N}_{\text {amine }}\right)_{\mathrm{ax}}\right]$ (BMf) corresponding to $A_{z}^{\text {est }}=$ $160.0 \times 10^{-4} \mathrm{~cm}^{-1}$ (see Scheme 2). On the other hand, given the donor groups available, species IIIA corresponds to quite a high $A_{z}$ value. The highest reasonable $A_{z}^{\text {est }}$ is obtained for the binding mode $\left[\left(2 \times \mathrm{O}_{\mathrm{Phen}}, \mathrm{COO}^{-}, \mathrm{H}_{2} \mathrm{O}\right)_{\mathrm{eq}^{-}}{ }^{-}\right.$ $\left.\left(\mathrm{N}_{\text {amine }}\right)_{\text {ax }}\right]$ (BMd), which corresponds to $A_{z}{ }^{\text {est }}=$ $165.5 \times 10^{-4} \mathrm{~cm}^{-1}$, compatible with the experimental value $\left(167.9 \times 10^{-4} \mathrm{~cm}^{-1}\right)$. However, this binding mode assumes that the amino group $\mathrm{N}(2) \mathrm{H}$ is deprotonated and noncoordinated, which is hardly probable, even if, not considering the carboxylate, this group has a lower macroscopic $\mathrm{p} K_{\mathrm{a}}$ 
$(\mathbf{V O}) \mathbf{L H}_{2}^{+}\left(\equiv \mathbf{I I} \rightarrow A_{z}=171.1 \times 10^{-4} \mathrm{~cm}^{-1}\right)$

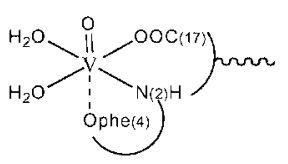

BMa1 $\left(A_{\bar{z}}^{\text {est }}=173.5 \times 10^{-4} \mathrm{~cm}^{-1}\right)$

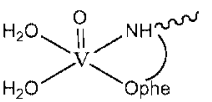

BMb $\left(A_{i}^{\text {est }}=170.2 \times 10^{-4} \mathrm{~cm}^{-1}\right)$

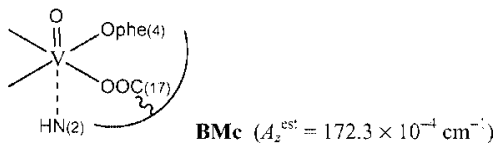

(VO)L

IIIA $\left(A_{z}=167.9 \times 10^{-4} \mathrm{~cm}^{-1}\right)$

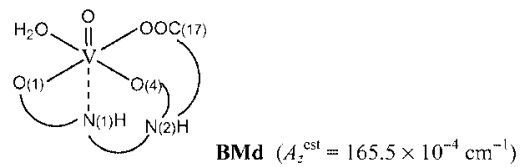

IIIB $\left(A_{3}=161.4 \times 10^{-4} \mathrm{~cm}^{-1-1}\right)$

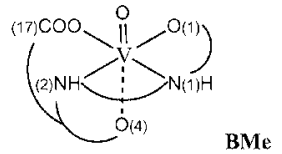

$\left(A_{z}^{\mathrm{cst}}=161.2 \times 10^{-4} \mathrm{~cm}^{-1}\right)$

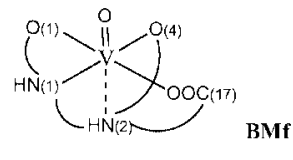

$\left(A_{z}^{\text {es: }}=160.0 \times 10^{-4} \mathrm{~cm}^{-}\right)$
Scheme 2. Schematic representation of the plausible structures for the main stoichiometries that form in the $\mathrm{V}^{\mathrm{IV}} \mathrm{O}$-salDPA system; the corresponding $A_{z}{ }^{\text {est }}$ values are also included. In some of these representations the numbering of atoms of salDPA used in Figure 1 is also included to specify more clearly to which atoms they correspond. For the EPR component IIIA, other plausible binding modes cannot be ruled out (see text).

$\left(\mathrm{p} K_{\mathrm{a} 2}=5.91\right)$ value. Possible binding modes that involve coordination of all groups with high $\mathrm{p} K_{\mathrm{a}}$ values are: e.g. $\left[\left(\mathrm{O}_{\text {Phen }}, \quad \mathrm{H}_{2} \mathrm{O}, \quad 2 \times \mathrm{N}_{\text {amine }}\right)_{\mathrm{eq}}\left(\mathrm{O}_{\text {Phen }}\right)_{\mathrm{ax}}\right] \quad\left(A_{z}{ }^{\text {est }}=\right.$ $\left.164.6 \times 10^{-4} \mathrm{~cm}^{-1}\right)$ and $\left[\left(2 \times \mathrm{O}_{\text {Phen }}, \mathrm{H}_{2} \mathrm{O}, \mathrm{N}_{\mathrm{amine}}\right)_{\mathrm{eq}}\left(\mathrm{N}_{\mathrm{amine}}\right)_{\mathrm{ax}}\right]$ $\left(A_{z}{ }^{\text {est }}=163.8 \times 10^{-4} \mathrm{~cm}^{-1}\right)$, these also correspond to relatively high $A_{z}$ values and cannot be completely ruled out. Scheme 2 summarises the set of the most plausible binding modes for $\mathrm{VOLH}_{2}$ and VOL.

The CD spectrum of the isolated $\mathrm{Na}\left[\mathrm{V}^{\mathrm{IV}} \mathrm{O}\right.$ (sal-L-DPA)] complex (see Figure $\mathrm{S} 4$ ) resembles the $\mathrm{CD}$ spectrum corresponding to $(\mathrm{VO}) \mathrm{L}^{-}$(Figure $3 \mathrm{~d}$ ). The spectrum in Figure $3 \mathrm{~d}$ is the calculated spectrum for stoichiometry $(\mathrm{VO}) \mathrm{L}^{-}$; therefore, it is a weighted average of the CD spectra of all isomeric complexes present, i.e. all complex species corresponding to the EPR components IIIA and IIIB.

\section{$V^{V} \mathrm{O}_{2}$ Complexes}

The complex formation constants derived from the potentiometric titrations carried out at different salDPA/ vanadium $(\mathrm{V})$ ratios are also included in Table 2. For the
$\mathrm{V}^{\mathrm{V}}$-salDPA system, the distribution diagram (Figure 6) includes the stoichiometries (oxidation state and charges omitted) $\mathrm{M}, \mathrm{MLH}_{2}, \mathrm{MLH}$ and $\mathrm{ML}\left(\mathrm{M}=\mathrm{V}^{\mathrm{V}} \mathrm{O}_{2}\right)$. Hereafter, $\mathrm{MLH}_{2}, \mathrm{MLH}$ and ML will be designated by $\left(\mathrm{VO}_{2}\right) \mathrm{LH}_{2}$, $\left(\mathrm{VO}_{2}\right) \mathrm{LH}^{-}$and $\left(\mathrm{VO}_{2}\right) \mathrm{L}^{2-}$, respectively. The system was also studied by ${ }^{51} \mathrm{~V}$ - and ${ }^{1} \mathrm{H}$ NMR and CD spectroscopy. Some of the ${ }^{51} \mathrm{~V}$ NMR spectra recorded are included in Figure 7 and the CD spectra are included in Figure 8. Under the experimental conditions used to obtain these spectra, as the $\mathrm{pH}$ was decreased the colour changed from yellow to yellow-grey and then to grey $(\mathrm{pH} \approx 4)$. For $\mathrm{pH}<5$ the $\mathrm{pH}$ was not stable and a solid precipitated. At $\mathrm{pH} \approx 4$ there was no important concentration of $\mathrm{V}^{\mathrm{V}}$ in solution as was indicated by the low intensity of the ${ }^{51} \mathrm{~V}$ NMR spectra. In the potentiometric titrations similar observations were made but in the experiments at lower vanadium concentrations (0.5-1 mM) no precipitation of any solid compound was detected upon decreasing the $\mathrm{pH}$. However, as the $\mathrm{pH}$ readings were not stable, only titration points for $\mathrm{pH}>5$

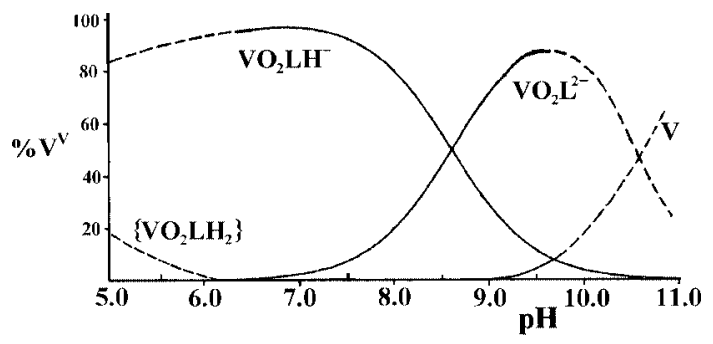

Figure 6. Approximate species distribution diagram for the complexes formed in the $\mathrm{V}^{\mathrm{V}}$-salDPA system for solutions for which $C_{\mathrm{V}}$ ca. $3.0 \mathrm{~mm}$ and $\mathrm{L} / \mathrm{M}=1\left(\mathrm{t}=25^{\circ} \mathrm{C}, I=0.2 \mathrm{M} \mathrm{KCl}\right)$. The potentiometric data suggest that the $\mathrm{V}^{\mathrm{V}_{-}}$-salDPA species that forms for $\mathrm{pH}$ $<6$ corresponds to a $\left(\mathrm{VO}_{2}\right) \mathrm{LH}_{2}$ stoichiometry. The full lines were calculated from the $\log \beta$ values included in Table 1 . The dashed lines are an estimate of the relative importance of the $\mathrm{V}^{\mathrm{V}}$-species present in solution, partly on the basis of the relative areas of the ${ }^{51} \mathrm{~V}$ NMR peaks.
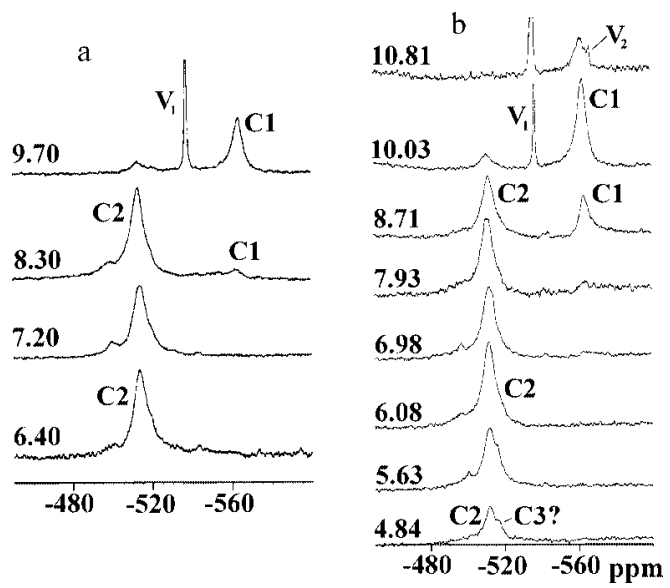

Figure 7. ${ }^{51} \mathrm{~V}$ NMR spectra, obtained at $131.404 \mathrm{MHz}$ and at $25.0 \pm 0.5^{\circ} \mathrm{C}$, of solutions containing sodium vanadate and salDPA. Spectra corresponding to two different sets of experiments are shown, (a) $C_{\mathrm{V}}$ ca. $3.0 \mathrm{~mm}$ and $\mathrm{L} / \mathrm{M}=1.27\left(\mathrm{D}_{2} \mathrm{O}\right.$ solution), the $\mathrm{pD}$ values are indicated in each spectrum; (b) $C_{\mathrm{V}}$ ca. $4.0 \mathrm{~mm}$ and $\mathrm{L} / \mathrm{M}=1.2\left(\mathrm{H}_{2} \mathrm{O}\right.$ solution $)$, the $\mathrm{pH}$ values are indicated in each spectrum. 

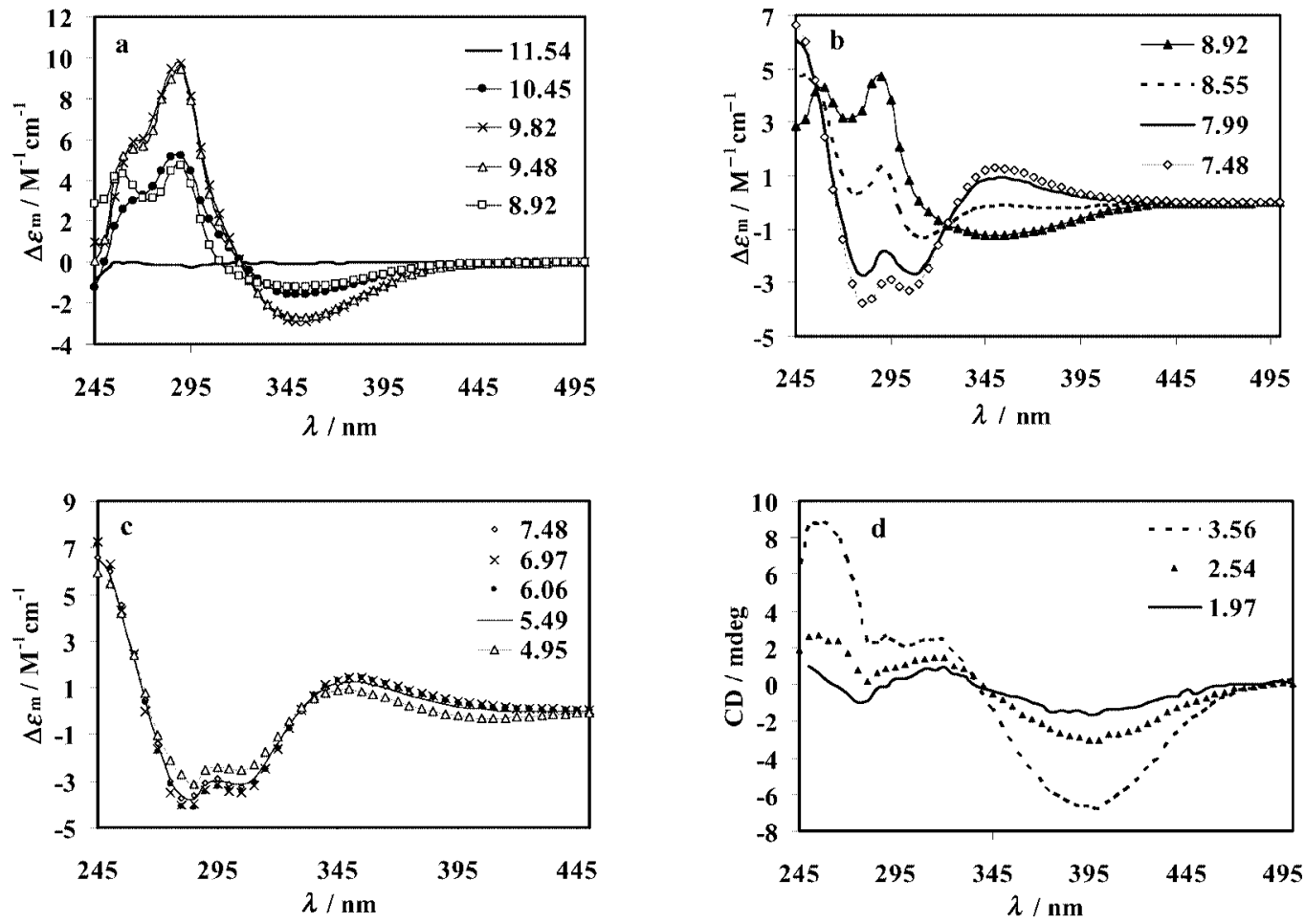

Figure 8. Some $\mathrm{CD}$ spectra recorded for the $\mathrm{V}^{\mathrm{V}} \mathrm{O}_{2}$-salDPA system at a 1.2:1 ligand/metal ion ratio at several $\mathrm{pH}$ values (indicated) and $C_{\mathrm{V}}=$ ca. $3 \mathrm{~mm}$. The measurements started at $\mathrm{pH}$ ca. 11.5 and were made by making successive additions of an $\mathrm{HCl}$ solution. For $\mathrm{pH}<$ 5 a grey precipitate started to form, and the amount of this precipitate increased for $\mathrm{pH}<4$. The $\mathrm{CD}$ spectra for $\mathrm{pH}<4$ were recorded from clear samples after filtration of the mixture. The CD spectra of species $\left(\mathrm{VO}_{2}\right) \mathrm{LH}^{-}$and $\left(\mathrm{VO}_{2}\right) \mathrm{LH}^{2-}$ calculated with the PSEQUAD programme ${ }^{[24]}$ by using the $\log \beta$ values included in Table 1 are shown in Section 8 of the Supporting Information.

were used in the calculations with the PSEQUAD programme.

In Figure 7 the ${ }^{51} \mathrm{~V}$ NMR peak at $-563 \mathrm{ppm}(\mathbf{C} 1)$, detected between ca. $\mathrm{pH} 11$ and 7.6, corresponds to the $\left(\mathrm{VO}_{2}\right) \mathrm{L}^{2-}$ species. In this complex the ligand is probably tetradentate and is coordinated by the two phenolate and two amine donors (see BMg in Scheme 3), as was observed in the $\mathrm{V}^{\mathrm{V}}$-pyran system where ${ }^{51} \mathrm{~V}$ NMR peaks also appeared at ca. -565 ppm. ${ }^{[15]}$ However, as this complex corresponds to a relatively intense CD signal (see below), structures involving the coordination of the $\mathrm{COO}^{-}$group instead of one $\mathrm{O}_{\text {phen }}$ or one $\mathrm{NH}_{\text {amine }}$ cannot be ruled out.

The broad peak around $-512 \mathrm{ppm}(\mathbf{C} 2)$, has a peak/ shoulder at $-500 \pm 2 \mathrm{ppm}$, and shoulder(s) may also be seen at $\approx-516 \pm 2 \mathrm{ppm}$. Apparently, the relative intensity of the peaks at ca. -512 and ca. $-500 \mathrm{ppm}$ does not change with $\mathrm{pH}$, so they correspond to isomeric forms of the same stoichiometry, $\left(\mathrm{VO}_{2}\right) \mathrm{LH}^{-}$. Scheme 3 includes several plausible structures for these species.

As mentioned above, for $\mathrm{pH}<5$ a precipitate forms, most of the $\mathrm{V}^{\mathrm{V}}$ is removed from the solution, and the ${ }^{51} \mathrm{~V}$ NMR signals are very weak. Upon addition of an $\mathrm{HCl}$ solution, this grey precipitate dissolves, forming a blue solution; therefore, the solid contains a $\mathrm{V}^{\mathrm{IV}}$ species. However, as neither the grey solid nor its mother solution show an EPR signal, most of it is probably vanadyl hydroxide (see also Section 6 in the Supporting Information).

In solutions initially containing $3 \mathrm{~mm} \mathrm{~V}$ and salDPA, a weak signal at ca. $-515 \mathrm{ppm}(\mathbf{C} 3)$ could be detected between ca. pH 5.6 and 4.0 (together with the peak $\mathbf{C 2}$ and at least four other peaks which presumably correspond to oligomeric vanadates, not shown in Figure 7). The dashed line in the $\mathrm{pH}$ range 5-6 in Figure 6 was estimated on the basis of these observations. It is reasonable to assume that this ${ }^{51} \mathrm{~V}$ NMR peak corresponds to complex $\left(\mathrm{VO}_{2}\right) \mathrm{LH}_{2}$, as suggested by the potentiometric calculations.

$\mathrm{CD}$ spectra were recorded for aqueous solutions containing sal-L-DPA at several $\mathrm{pH}$ values, but the $\Delta \varepsilon_{\mathrm{m}}$ values were approximately zero in the range $240-700 \mathrm{~nm}$. Several CD spectra recorded for the $\mathrm{V}^{\mathrm{V}}$-salDPA system are included in Figure 8 . The sal-L-DPA ligand itself has no significant CD spectrum for $\lambda>240 \mathrm{~nm}$ and no absorption for $\lambda>$ $320 \mathrm{~nm}$; therefore, the CD bands observed must mainly be metal-related induced CD signals. We expect that the efficiency of the sal-L-DPA donor groups in inducing dissymmetry in the metal-related bands follows the order $\mathrm{COO}^{-}>$ $\mathrm{N}(2)>\mathrm{N}(1)>>\mathrm{O}_{\mathrm{Phen},}{ }^{[31]}$ i.e. strong CD signals are expected only when $\mathrm{N}(2)$ and particularly $\mathrm{COO}^{-}$are coordinated to the metal centre.

At $\mathrm{pH}$ ca. 11.5 the $\Delta \varepsilon_{\mathrm{m}}$ values are approximately zero, so there are no $\mathrm{V}^{\mathrm{V}}$-sal-L-DPA complexes in solution. At $\mathrm{pH} 10.5$ the pattern of the CD spectrum is the same as that observed at $\mathrm{pH} 9.8$ or 9.5 , but $\left|\Delta \varepsilon_{\mathrm{m}}\right|^{\mathrm{pH} 10.4} \approx$ $1 / 2\left|\Delta \varepsilon_{\mathrm{m}}\right|^{\mathrm{pH}}{ }^{\mathrm{g} .8}$ or 9.4 (see Figure $8 \mathrm{a}$ ). These CD spectra correspond to the species $\left(\mathrm{VO}_{2}\right) \mathrm{L}^{2-}$. Between $\mathrm{pH} 11.4$ and 9.5, all CD spectra cross at ca. $325 \mathrm{~nm}, \Delta \varepsilon_{\mathrm{m}}=0$, indicating the presence of only one optically active species in equilibrium with the $\mathrm{V}^{\mathrm{V}}$ hydrolysis products. For $\mathrm{pH}<9.4$ the pattern 
C1

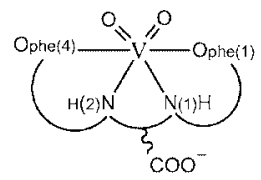

BMg

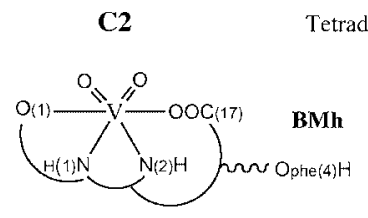

Tetradentate complexes

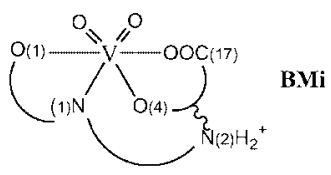

$\mathrm{C} 2$

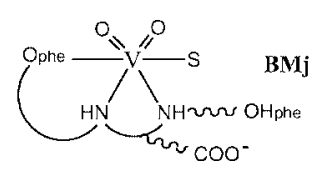

Tridentate complexes

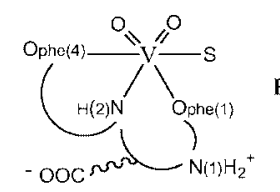

BMk

C3

Tridentate complex

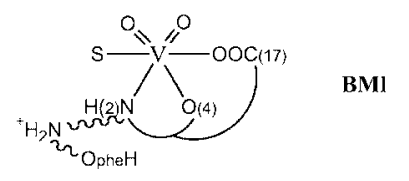

Scheme 3. Schematic representation of the plausible structures for the main stoichiometries that form in the $\mathrm{V}^{\mathrm{V}} \mathrm{O}_{2}$-salDPA system. In some of these representations the numbering of atoms of salDPA used in Figure 1 is also included to specify more clearly to which atoms they correspond. Note that, for each of the schematic binding modes represented, (i) more than one isomer may form, (ii) other plausible binding modes can be envisaged.

of the CD spectra gradually change, and between $\mathrm{pH} 8.9$ and 7.0 they show an isodichroic point, indicating the presence of two types of optically active species, $\mathrm{VO}_{2} \mathrm{~L}^{2-}$ and $\mathrm{VO}_{2} \mathrm{LH}^{-}$(Figure 8b). Between $\mathrm{pH} 7.5$ and 5.0, the spectra remain approximately the same and correspond to $\left(\mathrm{VO}_{2}\right)$ $\mathrm{LH}^{-}$(Figure 8c).

For lower $\mathrm{pH}$ values, precipitation of a dark-grey solid occurs. CD spectra could be obtained after filtering the mixture. Figure $8 \mathrm{~d}$ includes some of the spectra recorded, but $\Delta \varepsilon_{\mathrm{m}}$ values could not be obtained as the $\mathrm{V}^{\mathrm{V}}$ concentration in these solutions is not known. The pattern of these $\mathrm{CD}$ spectra differs from that corresponding to $\left(\mathrm{VO}_{2}\right) \mathrm{LH}^{-}$ (Figure 8c), so this optically active complex corresponds to a distinct stoichiometry, $\left(\mathrm{VO}_{2}\right) \mathrm{LH}_{2}$, as suggested by the potentiometric data.

Species C3, detected by ${ }^{51} \mathrm{~V}$ NMR and CD spectroscopy, probably corresponds to the binding mode BMI indicated in Scheme 3. This is the only reasonable way to obtain an optically active $\mathrm{V}^{\mathrm{V}}$-salDPA complex with a $\left(\mathrm{VO}_{2}\right) \mathrm{LH}_{2}$ stoichiometry, i.e. the $(5+6)$-chelate rings containing atoms $\mathrm{O}(2$ or 3) $-\mathrm{C}(17)-\mathrm{C}(9)-\mathrm{N}(2)-\mathrm{C}(10)-\mathrm{C}(11)-\mathrm{C}(16)-\mathrm{O}(4)$ (see Figure 1), which are involved in the chelate rings.

Species $\mathbf{C 2}$ corresponds to the CD spectra shown in Figure 8c (and in Figure S6) and to more than one isomer, as indicated by the ${ }^{51} \mathrm{~V}$ NMR spectrum, where at least two distinct broad peaks are detected: an intense one at $-512 \pm 2 \mathrm{ppm}$ and a weaker one at $-500 \pm 2 \mathrm{ppm}$; the difference in chemical shift between $\mathbf{C} 1$ and $\mathbf{C 2}$ indicates quite different binding modes. The broadness of the peaks may suggest a nonsymmetrical binding mode, BMh and Bmi, corresponding to a plausible hypothesis. For the tridentate structures such as $\mathbf{B M k}$ and particularly $\mathbf{B M j}$, we would expect a weak CD signal (see above), but this is not the case here. However, tridentate structures cannot be ruled out, as this appears to be the most reasonable explanation for the large difference in chemical shift between $\mathbf{C 1}$ and $\mathbf{C 2}$.

\section{Conclusions}

The reduced Schiff bases of salicylaldehyde with diaminopropionic acid (salDPA) and ornithine (salOrn), as well as the $\mathrm{V}^{\mathrm{IV}} \mathrm{O}^{2+}$ and $\mathrm{V}^{\mathrm{V}} \mathrm{O}_{2}{ }^{+}$complexes of salDPA were prepared and characterised in the solid state and in solution. The structure of one of the protonated forms of salDPA, $\mathrm{H}_{4} \mathrm{salDPA}^{+} \mathrm{Cl}^{-}$, was determined by X-ray diffraction. Complexation of $\mathrm{V}^{\mathrm{IV}} \mathrm{O}^{2+}$ and $\mathrm{V}^{\mathrm{V}} \mathrm{O}_{2}{ }^{+}$with salDPA in aqueous solution was studied by potentiometry, UV/Visible spectroscopy and circular dichroism, as well as by EPR spectroscopy for the $\mathrm{V}^{\mathrm{IV}} \mathrm{O}$-salDPA system and by ${ }^{1} \mathrm{H}$ - and ${ }^{51} \mathrm{~V}$ NMR spectroscopy for the $\mathrm{V}^{\mathrm{V}} \mathrm{O}_{2}-\mathrm{salDPA}$ system. The $\mathrm{V}^{\mathrm{IV}} \mathrm{O}-$ salOrn system was studied by potentiometry.

These reduced Schiff base ligands are less susceptible to hydrolysis than their corresponding Schiff base compounds, which we did not isolate in pure form. They also form much more stable complexes than the corresponding Schiff bases. As expected for a salen-type ligand derived from an ethylenediamine rather than a butylenediamine moiety, the $\mathrm{V}^{\mathrm{IV}} \mathrm{O}$ complexes formed with salDPA are much more stable than those formed with salOrn. In fact, in aqueous solutions containing 1:1 ligand/metal stoichiometry, no $\mathrm{V}^{\mathrm{IV}} \mathrm{O}$ hydrolytic products were detected in the $\mathrm{pH}$ range 4 to 11 in the salDPA system, while for the salOrn system significant concentrations of $\left[(\mathrm{VO})_{2}(\mathrm{OH})_{5}{ }^{-}\right]_{n}{ }^{[25]}$ formed in the $\mathrm{pH}$ ranges 5-7.5 and 10.5-12.

Practically only 1:1 complexes are formed. The main species formed have the composition (VO) $\mathrm{LH}_{2}{ }^{+}$and $(\mathrm{VO}) \mathrm{L}^{-}$in the $\mathrm{V}^{\mathrm{IV}} \mathrm{O}-$ salDPA system, (VO) $\mathrm{LH}_{2}{ }^{+},(\mathrm{VO}) \mathrm{LH}$ and $(\mathrm{VO}) \mathrm{L}^{-}$ in the $\mathrm{V}^{\mathrm{IV}} \mathrm{O}-$ salOrn system and $\left(\mathrm{VO}_{2}\right) \mathrm{LH}^{-}$and $\left(\mathrm{VO}_{2}\right) \mathrm{L}^{2-}$ in the $\mathrm{V}^{\mathrm{V}} \mathrm{O}_{2}$-salDPA system. Spectroscopic data provided information about the most probable binding mode of each stoichiometry of the vanadium-salDPA systems. In most cases, the $\mathrm{COO}^{-}$groups are involved in the coordination to $\mathrm{V}^{\mathrm{IV}} \mathrm{O}^{2+}$ or $\mathrm{V}^{\mathrm{V}} \mathrm{O}_{2}{ }^{+}$, so the binding modes of the ligand may differ from those typically found in vanadium-salen systems.

Globally salDPA is a very effective ligand for $\mathrm{V}^{\mathrm{IV}} \mathrm{O}^{2+}$ and $\mathrm{V}^{\mathrm{V}} \mathrm{O}_{2}{ }^{+}$, namely in the $\mathrm{pH}$ range $6-9$. The pendant carboxylate group may help the coupling of the salan moiety to other molecules that may target the compound to specific 
biological sites. Therefore, we anticipate the possibility of using salDPA systems as carriers of vanadium or other metal ions for this purpose.

\section{Experimental Section}

\section{Synthesis of Solid Compounds}

salDPA (1): Triethylamine ( $3 \mathrm{~g}, 29.8 \mathrm{mmol}$ ) was added to a suspension of L- or D,L-2,3-diaminopropionic acid (DPA) (2 g, $14.2 \mathrm{mmol}$ ) in methanol $(50 \mathrm{~mL})$ in order to neutralise the mixture. Small portions of a solution of salicylaldehyde in $\mathrm{MeOH}$ (3.6 g, $29.1 \mathrm{mmol}$ ) were slowly added to this mixture. The mixture became yellow, and this colour became stronger and stronger until the dissolution of DPA was completed. The solution was cooled in ice, and sodium borohydride $(2.4 \mathrm{~g}, 63.9 \mathrm{mmol})$ was slowly added. A white solid soon precipitated; it was filtered and suspended in $\mathrm{MeOH}$ for $3 \mathrm{~h}$. The solid was then filtered, washed with water and $\mathrm{MeOH}$ and dried under vacuum. Yield $62 \%$. The number of molecules of water of crystallization found in the several syntheses performed varied from 0 to 1 and the values reported are only examples of some of those found. Yield: $2.8 \mathrm{~g}, 60 \%$. For $\mathrm{H}_{3}$ sal-D,L-DPA, $\mathrm{C}_{17} \mathrm{H}_{20.6} \mathrm{~N}_{2} \mathrm{O}_{4.3}$ $\left[\mathrm{C}_{17} \mathrm{H}_{20} \mathrm{~N}_{2} \mathrm{O}_{4} \cdot 0.3 \mathrm{H}_{2} \mathrm{O}\right]$ (321.7): calcd. C 63.46, H 6.45, N 8.71; found $\mathrm{C} 63.6, \mathrm{H} 6.7, \mathrm{~N}$ 8.6. ${ }^{1} \mathrm{H}$ NMR $\left(300 \mathrm{MHz}, \mathrm{D}_{2} \mathrm{O}, \approx 25^{\circ} \mathrm{C}\right)$ : 4.30 (s, $5 \mathrm{H}, \mathrm{Ar}-\mathrm{CH} 2-\mathrm{N}$ and $-\mathrm{CH}-\mathrm{N}-), 3.55$ (d, $\left.2 \mathrm{H}, \mathrm{NH}-\mathrm{CH}_{2}\right)$, 6.92 (s, $\left.4 \mathrm{H}, \mathrm{CH}_{\text {aromatic }}\right), 7.28$ (d, $4 \mathrm{H}, \mathrm{CH}_{\text {aromatic }}$ ) ppm. A second method was also used; in the final stage the white solid was suspended in $\mathrm{MeOH}$, and the $\mathrm{pH}$ was lowered with a methanol solution of $\mathrm{HCl}(\mathrm{pH}<1.5)$. The solid dissolved, and ca. 30 min later another white solid precipitated. This was filtered and washed with water and $\mathrm{MeOH}$. (Yield: 37\%). From the mother solution, kept at room temperature for one week, white crystals (small needles) suitable for single-crystal $\mathrm{X}$-ray diffraction were obtained. Yield: $0.132 \mathrm{~g}, 37 \%$. For $\mathrm{H}_{4}$ sal-D,L-DPA.Cl (1A), $\mathrm{C}_{17} \mathrm{H}_{21} \mathrm{~N}_{2} \mathrm{O}_{4} \mathrm{Cl}$ (358.2): calcd. C 57.87, H 6.00, N 7.94; found C 58.0, H 6.3, N 7.9. For $\mathrm{H}_{4}$ sal-L-DPA $\cdot \mathrm{Cl}, \quad \mathrm{C}_{17} \mathrm{H}_{21.6} \mathrm{~N}_{2} \mathrm{O}_{4.3} \mathrm{Cl} \quad\left[\mathrm{C}_{17} \mathrm{H}_{21} \mathrm{~N}_{2} \mathrm{O}_{4} \mathrm{Cl} \cdot 0.3 \mathrm{H}_{2} \mathrm{O}\right]$ (358.2): calcd. C 56.99, H 6.08, N 7.82; found C 57.1, H 6.3, N 7.7.

sal-L-Orn (2): An ethanol solution $(5 \mathrm{~mL})$ of salicylaldehyde $(0.230 \mathrm{~mL} ; 2.2 \mathrm{mmol})$ was added to an aqueous solution $(20 \mathrm{~mL})$ of L-ornithine $(0.169 \mathrm{~g}, 1 \mathrm{mmol})$. The yellow solution was stirred for ca. $1 \mathrm{~h}$ and then cooled to ca. $0^{\circ} \mathrm{C}$. As a solution of sodium borohydride $(0.095 \mathrm{~g}, 2.5 \mathrm{mmol})$ in ethanol $(2 \mathrm{~mL})$ containing a few drops of a $\mathrm{NaOH}(4 \mathrm{~m})$ solution was slowly added, the yellow colour gradually disappeared. After ca. $2 \mathrm{~h}$, the $\mathrm{pH}$ was set to ca. 5.2 with $\mathrm{HCl}(3 \mathrm{M})$. The solution was kept in a refrigerator at ca. $4{ }^{\circ} \mathrm{C}$ for one week. A small amount of a white precipitate formed, which was filtered, washed with cold water, ethanol and ether and dried in vacuo. Yield: $0.051 \mathrm{~g}, 13 \%$. For $\mathrm{H}_{3}$ sal-L-Orn, $\mathrm{C}_{19} \mathrm{H}_{28.4} \mathrm{~N}_{2} \mathrm{O}_{6.7}$ $\left[\mathrm{C}_{19} \mathrm{H}_{24} \mathrm{~N}_{2} \mathrm{O}_{4} \cdot 2.7 \mathrm{H}_{2} \mathrm{O}\right]$ (393.0): calcd. C 58.06, H 7.54, N 7.13; found $\mathrm{C} 58.0, \mathrm{H} 7.5, \mathrm{~N} 7.1$.

sal-L-Lys (3): The procedure was identical to the one used for salL-Orn, but the white solid sal-L-Lys precipitated overnight. Yield: $28 \%$. The number of molecules of water of crystallization found in the several solids obtained varied from 2 to 3 , and the value included here corresponds to one of the batches. Yield: $0.114 \mathrm{~g}, 28 \%$. For $\mathrm{H}_{3}$ sal-L-Lys, $\mathrm{C}_{20} \mathrm{H}_{31.4} \mathrm{~N}_{2} \mathrm{O}_{6.7}\left[\mathrm{C}_{20} \mathrm{H}_{26} \mathrm{~N}_{2} \mathrm{O}_{4} \cdot 2.7 \mathrm{H}_{2} \mathrm{O}\right]$ (407.0): calcd. C 59.01, H 7.77, N 6.88; found $\mathrm{C} 59.0, \mathrm{H} 7.8, \mathrm{~N} 6.8$. The compound is not soluble in water or in ethanol/water (at least up to $10 \%$ ethanol).

van-D,L-DPA (4): A methanol solution $(5 \mathrm{~mL})$ of $o$-vanillin $(0.339 \mathrm{~g}$, $2.2 \mathrm{mmol}$ ) was added to a suspension of $\mathrm{D}, \mathrm{L}-2,3$-diaminopropionic acid (DPA) $(0.142 \mathrm{~g}, 1 \mathrm{mmol})$ in methanol $(10 \mathrm{~mL})$. Triethylamine was added in order to obtain a $\mathrm{pH}$ value of ca. 7.0. The yellow solution was stirred for $3 \mathrm{~h}$ at room temperature and then cooled to ca. $0{ }^{\circ} \mathrm{C}$. Sodium borohydride was then slowly added $(0.113 \mathrm{~g}$, $3.0 \mathrm{~mm}$ ), and the solution became colourless. A small amount of a white solid precipitated, which was washed with cooled water (ca. $4{ }^{\circ} \mathrm{C}$ ), methanol and ether and then dried in vacuo. Yield: $0.092 \mathrm{~g}$, ca. $22 \%$. For $\mathrm{H}_{3}$ van-D,L-DPA, $\mathrm{C}_{19} \mathrm{H}_{28.8} \mathrm{~N}_{2} \mathrm{O}_{8.4}$ $\left[\mathrm{C}_{19} \mathrm{H}_{24} \mathrm{~N}_{2} \mathrm{O}_{6} \cdot 2.4 \mathrm{H}_{2} \mathrm{O}\right]$ (419.6): calcd. C 54.38, H 6.92, N 6.65; found C 54.4, H 6.4, N 6.6.

Na[VIV $\mathbf{O}$ (salDPA)]: salDPA was $(0.322 \mathrm{~g}, 1 \mathrm{mmol})$ dissolved in $20 \mathrm{~mL}$ of ethanol/water (1:3), and a few drops of $\mathrm{NaOH}$ (4 M) were added to promote total dissolution. An aqueous solution $(2 \mathrm{~mL})$ of sodium acetate $(0.675 \mathrm{~g}, 5 \mathrm{mmol})$ was then added, followed by the addition of an aqueous solution $(2 \mathrm{~mL})$ of $\mathrm{VOSO}_{4} \cdot 5 \mathrm{H}_{2} \mathrm{O}$ $(0.26 \mathrm{~g}, 1 \mathrm{mmol})$. The solution became pink, and a pink solid precipitated, which was filtered, washed with cold water $\left(\approx 4{ }^{\circ} \mathrm{C}\right)$, ethanol and ether, and dried under vacuum. Yield: $0.0987 \mathrm{~g}, 23 \%$. For $\mathrm{Na}\left[\mathrm{V}^{\mathrm{IV}} \mathrm{O}\right.$ (sal-D,L-DPA)], $\quad \mathrm{C}_{17} \mathrm{H}_{16} \mathrm{~N}_{2} \mathrm{NaO}_{5} \mathrm{~V} \quad\left[\mathrm{C}_{17} \mathrm{H}_{16} \mathrm{~N}_{2} \mathrm{O}_{5} \mathrm{VNa} \cdot\right.$ 1.5 $\mathrm{H}_{2} \mathrm{O}$ ] (429.2): calcd. C 47.57, $\mathrm{H} 4.46, \mathrm{~N}$ 6.53, Na 5.36; found $\mathrm{C}$ 47.8, $\mathrm{H} \mathrm{4.7,} \mathrm{N} \mathrm{6.5,} \mathrm{Na} \mathrm{6.3.} \mathrm{All} \mathrm{procedures} \mathrm{were} \mathrm{performed} \mathrm{under}$ $\mathrm{N}_{2}$ and both $\mathrm{Na}\left[\mathrm{V}^{\mathrm{IV}} \mathrm{O}\left(\right.\right.$ sal-D,L-DPA)] and $\mathrm{Na}\left[\mathrm{V}^{\mathrm{IV}} \mathrm{O}\right.$ (sal-L-DPA)] were prepared.

$\mathbf{N a}\left[\mathbf{V}^{\mathbf{V}} \mathbf{O}_{2}\right.$ (salDPA)]: sal-D,L-DPA $(0.322 \mathrm{~g}, 1 \mathrm{mmol})$ was dissolved in $25 \mathrm{~mL}$ of water, and a few drops of $\mathrm{NaOH}(4 \mathrm{M})$ were added to promote total dissolution. An aqueous solution $(5 \mathrm{~mL})$ of ammonium vanadate was prepared, also containing a few drops of $\mathrm{NaOH}$ (4 M). Under vigorous stirring, the vanadate solution was slowly added to the salDPA solution. A solution of $\mathrm{HCl}(3 \mathrm{M})$ was then slowly added until $\mathrm{pH}$ ca. 8 was obtained. While adding the acid, a dark solid first appeared, but it disappeared upon stirring. The initial yellow colour became greenish. After $2 \mathrm{~h}$ of stirring, a greyish solid formed, it was filtered, and the filtrate was kept. After ca. $20 \mathrm{~h}$ a lemon-green solid was formed, which was filtered and washed with cold water $\left(\approx 4{ }^{\circ} \mathrm{C}\right)$, ethanol and ether, and dried under vacuum. Yield: $0.188 \mathrm{~g}, 40 \%$. For $\mathrm{Na}\left[\mathrm{VO}_{2}\right.$ (sal-D,L-DPA)], $\mathrm{C}_{17} \mathrm{H}_{20} \mathrm{~N}_{2} \mathrm{NaO}_{7} \mathrm{~V}\left[\mathrm{C}_{17} \mathrm{H}_{16} \mathrm{~N}_{2} \mathrm{O}_{5} \mathrm{VNa} \cdot 2 \mathrm{H}_{2} \mathrm{O}\right]$ (470.2): calcd. C 44.95, $\mathrm{H}$ 4.44, N 6.17, Na 5.05; found C 44.9, H 4.4, N 6.0, Na 4.6.

\section{Potentiometric Measurements}

All measurements were made in aqueous solution. The purity of the ligands was checked potentiometrically and the exact concentration of solutions was determined by the Gran method. ${ }^{[32]}$ The stock solution of $\mathrm{V}^{\mathrm{IV}} \mathrm{O}$ was prepared and standardised as reported earlier. ${ }^{[33,34]}$ The $\mathrm{H}_{3} \mathrm{O}^{+}$concentration in the stock solutions were determined by potentiometry. The $\mathrm{V}^{\mathrm{V}}$ stock solution was prepared by dissolving $\mathrm{KVO}_{3}$ (Sigma-Aldrich) in an accurately measured volume of a $\mathrm{KOH}$ solution of known molarity $(0.1977 \mathrm{M})$, and its $\mathrm{OH}^{-}$concentration was calculated by taking into account the total volume of the $\mathrm{V}^{\mathrm{V}}$ stock solution prepared.

All solutions were manipulated in an inert atmosphere (high purity $\mathrm{N}_{2}$ or purified argon). The ionic strength was adjusted to $0.20 \mathrm{M}$ $\mathrm{KCl}$ and the temperature was $25.0 \pm 0.1^{\circ} \mathrm{C}$. The $\mathrm{pH}$ was measured with an Orion $710 \mathrm{~A}$ precision digital $\mathrm{pH}$ meter equipped with an Orion Ross 8103BN type combined glass electrode, calibrated for hydrogen ion concentration as described earlier. ${ }^{[33]}$ The ionic product of water was $\mathrm{p} K_{\mathrm{w}}=13.76$.

The protonation constants of salDPA were determined from five titration curves of 4- to 8-mL samples with initial concentrations in the range 0.002 to $0.01 \mathrm{M}$. Those of sal-L-Orn were determined from five titration curves of 2- to 4-mL samples with a similar concentration range.

Stability constants of the $\mathrm{V}^{\mathrm{IV}} \mathrm{O}$-salDPA system were determined by potentiometric titrations of six $10.0-\mathrm{mL}$ samples. The metal con- 
centrations were in the range $0.0005-0.003 \mathrm{M}$, and the $\mathrm{L} / \mathrm{M}$ ratio was from 0.7 to 4 . Titrations were normally performed from $\mathrm{pH}$ 2.0 up to 11 , unless very extensive hydrolysis, precipitation (only for $\mathrm{L} / \mathrm{M}=0.7$, at $\mathrm{pH}=4.0$ ) or very slow equilibration was detected, with $\mathrm{KOH}$ solution of known concentration (ca. $0.2 \mathrm{M}$ ) under a purified argon atmosphere. For the $\mathrm{V}^{\mathrm{IV}} \mathrm{O}$-sal-L-Orn system, the metal concentrations were in the range $0.001-0.004 \mathrm{M}$, and the $\mathrm{L} /$ $\mathrm{M}$ ratios varied from 1 to 4 . Titrations were normally performed from $\mathrm{pH} 2.0$ up to 11 in a $5-\mathrm{mL}$ thermostatted cell, by using the same criteria as for the $\mathrm{V}^{\mathrm{IV}} \mathrm{O}-$-salDPA system.

The stability constants of the $\mathrm{V}^{\mathrm{V}} \mathrm{O}_{2}$-salDPA system were also determined by potentiometric titrations of six $10.0 \mathrm{~mL}$ samples from $\mathrm{pH} 12$ to ca. 4 (or down to $\mathrm{pH}$ ca. 5 for the more concentrated samples, as some precipitation was detected at $\mathrm{pH}<5$ ) with an $\mathrm{HCl}$ solution of known concentration (ca. $0.2 \mathrm{M}$ ). The reversibility of the $\mathrm{V}^{\mathrm{V}}$ complexation was checked for three L/M ratios by titrating samples starting from $\mathrm{pH}$ ca. 5. The reproducibility of titration points included in the evaluation was within $0.005 \mathrm{pH}$ units in the $\mathrm{pH}$ range 5-11.

The concentration stability constants $\beta_{p q r}=\left[\mathrm{M}_{p} \mathrm{~L}_{q} \mathrm{H}_{r}\right] /[\mathrm{M}]^{p}[\mathrm{~L}]^{q}[\mathrm{H}]^{r}$ were calculated by using the PSEQUAD computer programme. ${ }^{[24]}$ The formation of the following $\mathrm{V}^{\mathrm{IV}} \mathrm{O}$ hydroxido complexes was taken into account: $\left[\mathrm{V}^{\mathrm{IV}} \mathrm{O}(\mathrm{OH})\right]^{+},\left[\left(\mathrm{V}^{\mathrm{IV}} \mathrm{O}\right)_{2}(\mathrm{OH})_{2}\right]^{2+},\left[\left(\mathrm{V}^{\mathrm{IV}} \mathrm{O}\right)_{2^{-}}\right.$ $\left.(\mathrm{OH})_{5}\right]^{-}$and $\left[\mathrm{V}^{\mathrm{IV}} \mathrm{O}(\mathrm{OH})_{3}\right]^{-} .{ }^{[25,35,36]}$ As is discussed in ref. ${ }^{[25]}$, the $\log \beta$ of $\left[\left(\mathrm{V}^{\mathrm{IV}} \mathrm{O}\right)_{2}(\mathrm{OH})_{5}\right]^{-}$and $\left[\mathrm{V}^{\mathrm{IV}} \mathrm{O}(\mathrm{OH})_{3}\right]^{-}$are not known accurately. Therefore, the calculations for $\mathrm{pH}>4$ may not be entirely reliable, particularly for systems and experimental conditions where these $\mathrm{V}^{\mathrm{IV}} \mathrm{O}$-hydroxido complexes have significant concentrations. For the $\mathrm{V}^{\mathrm{IV}} \mathrm{O}$-salDPA this is not the case, but for the salOrn system some inaccuracies may result from this. For the $\mathrm{V}^{\mathrm{V}}$ systems, the stability constants were similarly defined, where $\mathrm{M}$ refers to $\mathrm{VO}_{2}{ }^{+}$. The speciation of vanadate into monomeric, dimeric, tetrameric, pentameric and decameric species ${ }^{[37]}$ was taken into account.

\section{Spectroscopic Measurements}

General: IR spectra were recorded either with a BioRad FTS 3000 MX FTIR or with a Jasco FTIR 430 spectrometer. Visible spectra were recorded either with a Hitachi U-2000 or a PerkinElmer Lambda 9 UV/Vis/NIR spectrophotometer. The CD spectra were recorded with a JASCO 720 spectropolarimeter, either with a red-sensitive photomultiplier (EXEL-308) suitable for the 400 $1000 \mathrm{~nm}$ range or with the photomultiplier suitable for the 200 $700 \mathrm{~nm}$ range. The EPR spectra were recorded at $77 \mathrm{~K}$ (with glass made by freezing solutions in liquid nitrogen) with a Bruker ESP 300E X-band spectrometer. The ${ }^{1} \mathrm{H}$ - and ${ }^{51} \mathrm{~V}$ NMR spectra were obtained with a Varian Unity-500 NMR spectrometer operating at 499.824 and $131.404 \mathrm{MHz}$, respectively, by using a 5-mm-broadband probe and a controlled-temperature unit set at $25 \pm 1^{\circ} \mathrm{C}$. Most of the ${ }^{1} \mathrm{H}$ NMR spectra were obtained with a Varian Unity 300 spectrometer also at ca. $25^{\circ} \mathrm{C}$

UV/Vis and CD Spectroscopy: All measurements were made in water. The temperature was kept at $25.0 \pm 0.3{ }^{\circ} \mathrm{C}$ with circulating water. Unless otherwise stated, by visible (Vis) or circular dichroism (CD) spectra we mean a representation of $\varepsilon_{\mathrm{m}}$ or $\Delta \varepsilon_{\mathrm{m}}$ values vs. $\lambda$ $\left[\varepsilon_{\mathrm{m}}\right.$ : absorption $/\left(b C_{\mathrm{M}}\right)$ and $\Delta \varepsilon_{\mathrm{m}}$ : differential absorption/ $\left(b C_{\mathrm{M}}\right)$, where $b$ : optical path and $C_{\mathrm{M}}$ : total $\mathrm{V}^{\mathrm{IV}}$ or $\mathrm{V}^{\mathrm{V}}$ concentration]. The spectral range covered was normally 350-900 (Vis) and either 240 600 or $400-1000 \mathrm{~nm}(\mathrm{CD})$. All measurements and operations of the spectropolarimeter were computer-controlled. Normally the spectra were recorded by changing the $\mathrm{pH}$ with approximately fixed total vanadium and ligand concentrations. The CD spectra of polycrystalline samples were obtained as described in ref. ${ }^{[38]}$
EPR Spectroscopy: In the absence of ethylene glycol, a relatively broad background was present in most of the frozen solution EPR spectra; therefore, most spectra were run with aqueous solutions containing $5 \%$ of ethylene glycol. The $\mathrm{V}^{\mathrm{IV}} \mathrm{O}$ EPR spectra were simulated by using a programme by Rockenbauer and Korecz. ${ }^{[30]}$ The EPR spectra help to elucidate which groups coordinate in solution. ${ }^{[26]}$ For the $\mathrm{V}^{\mathrm{IV}} \mathrm{O}$ systems, we used the additivity rule to estimate the hyperfine coupling constant $A_{z}{ }^{\text {est }}$ (see above).

${ }^{1} \mathbf{H}$ - and ${ }^{51} \mathrm{~V}$ NMR Spectroscopy: All samples were prepared at room temperature immediately before the acquisition of the NMR spectra. Ligand solutions for the ${ }^{1} \mathrm{H}$ NMR pH titrations were prepared in $\mathrm{D}_{2} \mathrm{O}(99.995 \% \mathrm{D})$ by weighing the appropriate amount of the ligand in order to have the desired concentration. The $\mathrm{pD}$ values of these solutions were adjusted with $\mathrm{DCl}$ and $\mathrm{CO}_{2}$-free $\mathrm{NaOD}$ solutions, and measured by using either a Crison MicropH 2002 $\mathrm{pH}$-meter with an Ingold 405-M5 combined electrode, or a Thermo Orion 420A+ $\mathrm{pH}$ meter with a Mettler Toledo U402-M3-S7/200 combined microelectrode (all calibrated at $20 \pm 1{ }^{\circ} \mathrm{C}$ with standard aqueous buffers at $\mathrm{pH} 4.0$ and 7.0). The final values of $\mathrm{pD}$ were determined from $\mathrm{pD}=\mathrm{pH}^{*}+0.40$, where $\mathrm{pH}^{*}$ corresponds to the reading of the $\mathrm{pH}$ meter. ${ }^{[39]}$ To obtain ${ }^{51} \mathrm{~V}$ NMR spectra, the solutions containing the $\mathrm{V}^{\mathrm{V}}$-salDPA complexes were normally prepared by adding the appropriate amounts of the ligand salDPA to aqueous sodium vanadate solutions of known concentrations and at $\mathrm{pH}$ ca. $11-12$ in order to have the desired $\mathrm{L} / \mathrm{M}$ ratios $(\mathrm{L} / \mathrm{M}=1-$ 1.2). The initial $\mathrm{V}^{\mathrm{V}}$ concentration in the samples was 3 to $5 \mathrm{~mm}$. The measurements normally started at $\mathrm{pH}$ ca. 12 and were continued down to $\mathrm{pH} 4$ (in one set of experiments down to $\mathrm{pD} 1.8$ ) by addition of an $\mathrm{HCl}$ solution. In these experiments, a dark grey precipitate formed at $\mathrm{pH}<4-5$ (depending on the concentrations), but as the solid settled at the bottom of the NMR tubes, NMR spectra could be obtained from the clear solution. For the acquisition of ${ }^{1} \mathrm{H}$ NMR spectra from which data shown in Figure $\mathrm{S} 1$ was obtained, a ca. 5-mm solution of salDPA was prepared at $\mathrm{pD}$ ca. 13 in $\mathrm{D}_{2} \mathrm{O}$, by addition of $\mathrm{CO}_{2}$-free $\mathrm{NaOD}$. The measurements were performed down to $\mathrm{pH} 1$ by addition of $\mathrm{DCl}$ (or $\mathrm{NaOD}$, whenever necessary). For $\mathrm{pH}<5$ the salDPA started to precipitate, but as it agglomerated at the bottom of the NMR tubes, the spectra could be obtained from the clear solution in the upper part. The ${ }^{1} \mathrm{H}$ - and ${ }^{51} \mathrm{~V}$ NMR chemical shifts were referenced to DSS (sodium $\left[2,2,3,3-\mathrm{D}_{4}\right]$-3-trimethylsilylpropionate) at $0 \mathrm{ppm}$ and to a $\mathrm{VOCl}_{3}$ external solution at $0 \mathrm{ppm}$, respectively. ${ }^{51} \mathrm{~V}$ NMR acquisition parameters were: $33 \mathrm{kHz}$ spectral width, $30 \mu$ s pulse width, $1 \mathrm{~s}$ acquisition time and $10 \mathrm{~Hz}$ line broadening. The signal intensities of the NMR resonances were obtained by using the line-fitting routine supplied with the NUTS ${ }^{\mathrm{TM}}$ PC-based NMR spectral analysis programme. ${ }^{[40]}$

X-ray Crystal Structure Determination of 1: Three-dimensional room temperature X-ray data were collected with a Bruker Smart 1000 CCD instrument by the $\varphi-\omega$ scan method. Reflections were measured from a hemisphere of data collected from frames each covering $0.3^{\circ}$ in $\omega$. Of the 10878 reflections measured, all were corrected for Lorentz and polarization effects and for absorption by multiscan methods based on symmetry-equivalent and repeated reflections, and 1765 independent reflections exceeded the significance level $(|F| \sigma|F|)>4$.0. Complex scattering factors were taken from the programme package SHELXTL, ${ }^{[41]}$ implemented on a Pentium computer. The structures were solved by direct methods and refined by full-matrix least-squares on $F^{2}$. Hydrogen atoms were left to refine freely with isotropic thermal parameters, except for hydrogen atoms of $\mathrm{N}(1), \mathrm{O}(4), \mathrm{C}(8)$ and $\mathrm{C}(9)$, which were localised in the Fourier map and then fixed to the corresponding atoms. Refinement was performed with the allowance for thermal anisot- 
ropy of all non-hydrogen atoms. Complex scattering factors were taken from the programme package SHELXTL. Further details of the crystal structure determination and X-ray data are given in the Supporting Information (Section 10). CCDC 602814 (for 1A) contains the supplementary crystallographic data for the structure reported in this paper. These data can be obtained free of charge from the Cambridge Crystallographic Data Centre via www.ccdc.cam.ac.uk/data_request/cif.

Supporting Information (see footnote on the first page of this article):

1. Infrared spectra of the compounds.

2. ${ }^{1} \mathrm{H}$ NMR chemical shifts of salDPA as a function of $\mathrm{pD}$.

3. Speciation in the $\mathrm{V}^{\mathrm{IV}} \mathrm{O}-$ salOrn system.

4. CD spectra of $\mathrm{V}^{\mathrm{IV}} \mathrm{O}-$ salDPA solutions at $\mathrm{pH}>11$.

5. Representation of $\varepsilon_{\mathrm{m}}$ values vs. $\mathrm{pH}$ for $\mathrm{V}^{\mathrm{IV}} \mathrm{O}-$-salDPA solutions.

6. Circular dichroism spectra of solid polycrystalline samples.

7. Structures of ligands synthesized in this work for which complex formation in solution was not studied.

8. Circular dichroism spectra of $\left(\mathrm{VO}_{2}\right) \mathrm{LH}^{-}$and $\left(\mathrm{VO}_{2}\right) \mathrm{L}^{2-}$.

9. Comparison of the $\mathrm{V}^{\mathrm{V}}$-salDPA species concentration estimated from the ${ }^{51} \mathrm{~V}$ NMR spectra and the distribution diagram.

10. Crystal and structural data for $\mathrm{H}_{4} \mathrm{salDPA}^{+} \cdot \mathrm{Cl}^{-}(\mathbf{1 A})$.

\section{Acknowledgments}

This work was carried out in the frame of a COST D21 project. The authors are grateful to the National Research Fund (OTKA NI61786 and OTKA T49417), to the Hungarian Academy of Sciences, the Fundo Europeu para o Desenvolvimento Regional, Fundação para a Ciência e Tecnologia, the POCI Programme (project POCI/56949/QUI/2004 and POCI/55985/QUI/2004), the Hungarian-Portuguese Intergovernmental S \& $\mathrm{T}$ Cooperation Programme for 2004-2005, University of A Coruña and the SpanishPortuguese Bilateral Programme (Acção Integrada E-56/05). We also thank Tamás Gajda for supplying some of the sal-D,L-DPA ligand used in the preliminary experiments.

[1] K. H. Thompson, J. H. McNeill, C. Orvig, Chem. Rev. 1999, 99, 2561-2571.

[2] K. H. Thompson, C. Orvig, J. Chem. Soc., Dalton Trans. 2000, 2885-2892.

[3] C. Orvig, K. H. Thompson, Coord. Chem. Rev. 2001, 219-221, 1033-1053.

[4] H. Sakurai, Y. Kojima, Y. Yoshikawa, K. Kawabe, H. Yasui, Coord. Chem. Rev. 2002, 226, 187-198.

[5] A. E. Evangelou, Crit. Rev. Oncol./Hematol. 2002, 42, 249-265.

[6] P. Kopf-Maier, H. Kopf, Z. Naturforsch., Teil B 1979, 84, 805.

[7] C. Djorgevitz in Metal Ions in Biological Systems (Eds.: H. Sigel, A. Sigel), Marcel Dekker, New York, 1995, vol. 31, p. 596.

[8] S. J. D. Karlish, Y. Shechter, Nature 1980, 284, 556.

[9] G. R. Dubyak, A. Kleinzeller, J. Biol. Chem. 1980, 255, 5306.

[10] C. E. Heyliger, A. G. Tahiliani, J. H. McNeill, Science 1985, $227,1474$.

[11] J. Meyerovitch, Z. Farfel, J. Sack, Y. Schechter, J. Biol. Chem. 1987, 262, 609 .

[12] A. S. Tracey, M. J. Gresser, Proc. Natl. Acad. Sci. USA 1986, $83,609$.

[13] N. Durai, G. Saminathan, J. Clin. Biochem. Nutr. 1997, 22, 3139.
[14] J. M. Lacoste, J. Duhault, D. Ravel, EUR Pat. Appl. EP $521,787,1993$

[15] I. Correia, J. Costa Pessoa, M. T. Duarte, R. T. Henriques, M. F. Minas da Piedade, L. Veiros, T. Jakusch, A. Dornyei, T. Kiss, M. M. C. A. Castro, C. F. G. C. Geraldes, F. Avecilla, Chem. Eur. J. 2004, 10, 2301-2317.

[16] G. Verquin, G. Fontaine, M. Bria, E. Zhilinskaya, E. Abi-Aad, A. Aboukais, B. Baldeyrou, C. Bailly, J. L. Bernier, J. Biol. Inorg. Chem. 2004, 9, 345-353.

[17] I. Correia, J. Costa Pessoa, M. T. Duarte, M. F. Minas da Piedade, T. Jackush, T. Kiss, M. M. C. A. Castro, C. F. G. C. Geraldes, F. Avecilla, Eur. J. Inorg. Chem. 2005, 732-744.

[18] A. Jancsó, Z. Paksi, S. Mikkola, A. Rockenbauer, T. Gajda, J. Inorg. Biochem. 2005, 99, 1480-1489.

[19] P. O’Brien, S. Mahmood, M. A. Malik, M. Motevalli, P. B. Nunn, Tetrahedron 1998, 54, 5721-5730.

[20] D. H. Williams, I. Fleming in Spectroscopic Methods in Organic Chemistry, 5th ed., McGraw-Hill, London, 1995, pp. 42-49.

[21] G. Socrates, Infrared and Raman Characteristic Group Frequencies. Tables and Charts, 3rd ed., John Wiley \& Sons, Chichester, 2001, pp. 108-113.

[22] R. M. Silverstein, G. C. Bassler, T. C. Morril, "IR Spectroscopy" in Spectrometric Identification of Organic Compounds, 5th ed., John Wiley \& Sons, New York, 1991, pp. 122125.

[23] R. L. Shriner, C. K. F. Hermann, T. C. Morrill, D. Y. Curtin, R. C. Fuson, The Systematic Identification of Organic Compounds, 8th ed., John Wiley \& Sons, 2004, p. 194-227.

[24] L. Zekany, I. Nagypal in Computational Methods for the Determination of Stability Constants (Ed.: D. Leggett), Plenum, New York, 1985, pp. 291-353.

[25] L. F. Vilas Boas, J. Costa Pessoa, "Vanadium" in Comprehensive Coordination Chemistry (Eds.: G. Wilkinson, R. D. Gillard, J. A. McCleverty), Pergamon, Oxford, 1987, vol. 3, ch. 33, pp. 453-583.

[26] N. D. Chasteen in Biological Magnetic Resonance (Eds.: J. Lawrence, L. J. Berliner, J. Reuben), Plenum, New York, 1981; vol. 3 , ch. 2, pp. 53-119.

[27] T. Jakusch, P. Buglyó, I. Tomaz, J. Costa Pessoa, T. Kiss, Inorg. Chim. Acta 2002, 339, 119-128.

[28] T. S. Smith, C. A. Root, J. W. Kampf, P. G. Rasmussen, V. L. Pecoraro, J. Am. Chem. Soc. 2000, 122, 767-775.

[29] A. J. Tasiopoulos, A. N. Troganis, A. E. Evangelou, C. P. Raptopoulou, A. Terzis, Y. Deligiannakis, T. A. Kabanos, Eur. J. Chem. 1999, 5, 910-921.

[30] A. Rockenbauer, L. Korecz, Appl. Magn. Reson. 1996, 10, 29 43.

[31] H. Sigel, R. B. Martin, Chem. Rev. 1982, 82, 385-426.

[32] G. Gran, Acta Chem. Scand. 1950, 4, 559-575.

[33] J. Costa Pessoa, T. Gajda, R. D. Gillard, T. Kiss, S. M. Luz, J. J. G. Moura, I. Tomaz, J. P. Telo, I. Torok, J. Chem. Soc., Dalton Trans. 1998, 3587-3600.

[34] I. Nagypál, I. Fábián, Inorg. Chim. Acta 1982, 61, 109-113.

[35] A. Komura, M. Hayashi, H. Imanaga, Bull. Chem. Soc. Jpn. 1977, 50, 2927-2931.

[36] R. P. Henry, P. C. H. Mitchell, J. E. Prue, J. Chem. Soc., Dalton Trans. 1973, 1156-1159.

[37] L. Pettersson, B. Hedman, I. Andersson, N. Ingri, Chem. Scr. 1983, 22, 254-264.

[38] J. Costa Pessoa, M. J. Calhorda, I. Cavaco, P. J. Costa, I. Correia, D. Costa, L. Vilas-Boas, V. Felix, R. D. Gillard, R. T. Henriques, R. Wiggins, Dalton Trans. 2004, 2855-2866.

[39] P. K. Glasoe, F. A. Long, J. Phys. Chem. 1960, 64, 188-190.

[40] NUTS-NMR, Spectroscopic Data Processing Software, Acorn NMR, Fremont, CA, USA, 1999.

[41] G. M.Sheldrick, SHELXTL Bruker Analytical X-ray System, Madison, WI, 1997.

Received: April 5, 2006

Published Online: August 24, 2006 